\title{
Dermomyotome-derived endothelial cells migrate to the dorsal aorta to support hematopoietic stem cell emergence.
}

Pankaj Sahai-Hernandez ${ }^{\star 1}$, Claire Pouget ${ }^{\star 1,2}$, Ondřej Svoboda ${ }^{1,3}$, David Traver ${ }^{1,4 \#}$

${ }^{1}$ Department of Cellular and Molecular Medicine, University of California at San Diego, La Jolla, California, U.S.A.

${ }^{2}$ Current address: Angiocrine Bioscience, San Diego, California, U.S.A.

${ }^{3}$ Current address: Department of Cell Differentiation, Institute of Molecular Genetics, Academy of Sciences of the Czech Republic v.v.i., Prague, Czech Republic.

${ }^{4}$ Section of Cell and Developmental Biology, Division of Biological Sciences, University of California at San Diego, La Jolla, California, U.S.A.

${ }^{*}$ Authors contributed equally

\#Author for correspondence: dtraver@ucsd.edu 


\section{Abstract}

Development of the dorsal aorta is a key step in the establishment of the adult bloodforming system, since hematopoietic stem and progenitor cells (HSPCs) arise from ventral aortic endothelium in all vertebrate animals studied. Work in zebrafish has demonstrated that arterial and venous endothelial precursors arise from distinct subsets of lateral plate mesoderm. Earlier studies in the chick showed that paraxial mesoderm generates another subset of endothelial cells that incorporate into the dorsal aorta to replace HSPCs as they exit the aorta and enter circulation. Here we show that a similar process occurs in the zebrafish, where a population of endothelial precursors delaminates from the somitic dermomyotome to incorporate exclusively into the developing dorsal aorta. Whereas somite-derived endothelial cells (SDECs) lack hematopoietic potential, they act as local niche to support the emergence of HSPCs from neighboring hemogenic endothelium. Thus, at least three subsets of endothelial cells (ECs) contribute to the developing dorsal aorta: vascular ECs, hemogenic ECs, and SDECs. Taken together, our findings indicate that the distinct spatial origins of endothelial precursors dictate different cellular potentials within the developing dorsal aorta. 


\section{Introduction}

The primitive vascular network, which integrates into all organ systems in the developing organism, arises from endothelial precursors termed angioblasts (Risau and Flamme, 1995). To form a functional vascular network, angioblasts must first differentiate into a variety of distinct arterial and venous endothelial cell (EC) types, including hemogenic, endocardial, and blood brain barrier ECs (Aird, 2007; Herbert and Stainier, 2011). EC differentiation is thought to initiate midway through somitogenesis, as angioblasts migrate to the embryonic midline and coalesce to form the vascular tube (Herbert et al., 2009; Isogai et al., 2003; Jin et al., 2005). The current view states that equipotent angioblasts undergo successive steps of differentiation that, along with cues from local microenvironments, give rise to specialized subsets of ECs (Atkins et al., 2011; Marcelo et al., 2013). However, this view does not take into account putative differences in EC function as a result of different developmental origins. Rather, exposure to embryonic signaling cascades mediated via Wnt (Hubner et al., 2017), Hedgehog (Hh)(Gering and Patient, 2005; Vokes and McMahon, 2004; Wilkinson et al., 2012; Williams et al., 2010), Vascular Endothelial Growth Factor (VEGF) (Casie Chetty et al., 2017; Hong et al., 2006; Lawson et al., 2003; Lawson et al., 2002; Wythe et al., 2013), and Notch molecules are thought to differentially instruct equipotent angioblasts to each distinct endothelial cell fate (Fang et al., 2017; Lawson et al., 2001; Siekmann and Lawson, 2007; Zhong et al., 2001).

Lateral plate mesoderm (LPM) is known to be the primary source of ECs across vertebrate phyla (Potente and Makinen, 2017). However, recent findings have suggested that ECs can arise from distinct mesodermal derivatives, including extraembryonicderived erythromyeloid progenitors (EMPs), that contribute extensively to the murine kidney vasculature (Plein et al., 2018). Similarly, there is evidence in rodents and other amniotes, that paraxial mesoderm (PM) also generates a contingent of ECs that contribute to the embryonic vasculature (Ambler et al., 2001; Esner et al., 2006; Noden, 1989; Pardanaud et al., 1996; Pouget et al., 2006; Pouget et al., 2008; Wilting et al., 1995; Yvernogeau et al., 2012). Specifically, these ECs arise from a transient somitic compartment known as the dermomyotome (Eichmann et al., 1993; Ema et al., 2006; Pouget et al., 2008; Yvernogeau et al., 2012), where skeletal hypaxial muscle progenitors 
(skMPs) reside (Tozer et al., 2007). These skMPs give rise to migrating myoblasts that incorporate into the ventral body wall and limb musculature (Schienda et al., 2006) The existence of somite-derived endothelial cells, and their function, in other vertebrate species, such as zebrafish, is incompletely understood.

Here, using a combination of molecular and genetic approaches, we identify a population of somite-derived endothelial cells (SDECs) in zebrafish that arises from the dermomyotome. SDECs contribute mainly to the anterior portion of the dorsal aorta. Within the somite, EC-fate acquisition occurs in a sequential manner, concomitant with the epithelialization of each somite and the migration of angioblasts towards the midline of the embryo. We show that Wnt signaling is a key regulator of the distribution of ECs within the somite, whereas Notch signaling is necessary for skeletal muscle progenitor cell maintenance. Finally, epistasis experiments indicate that SDECs arise from bipotent precursors within the somite, with skMPs showing competency to become ECs in a NPAS4I (cloche (Stainier et al., 1995)) -dependent manner. Single cell RNA sequencing (scRNA-seq) of purified ECs identified SDECs as well as additional subsets of EC types with distinct molecular signatures. Collectively, these findings shift the current paradigm of vascular origins and indicate that there are distinct pools of endothelial progenitors that are molecularly and functionally distinct as early as the end of gastrulation. 


\section{Results}

\section{Somites Give Rise to Etv2 ${ }^{+}$Endothelial Cells Concomitant with Somite Epithelization}

In zebrafish, most ECs originate from the LPM (Jin et al., 2005); however, recent studies have suggested that somites also produce ECs that integrate into the vascular cord (Nguyen et al., 2014), but these remain incompletely defined. Therefore, we first aimed to characterize the development of SDECs. To accomplish this, we used confocal timelapse imaging in etv2:GFP transgenic zebrafish (Veldman and Lin, 2012), injected with mOrange2:CAAX mRNA, which have early endothelial cells marked by GFP with cell boundaries demarcated with mOrange2. As previously described (Veldman and Lin, 2012), beginning at the 10 somite stage (ss), we observed a line of Etv2:GFP+ ECs along the most medial part of the LPM (Figure 1A); we did not detect any Etv2:GFP+ cells in the somite at this stage (Figure 1A). Initiating at the $12 \mathrm{ss}$, we noted Etv2:GFP+ cells in the lateral lip of the somitic compartment (Figure 1B). After the onset of Etv2:GFP expression, somite-derived Etv2:GFP+ cells round up (Figure 1C and 1D), delaminate from the somite, then integrate into the cohort of LPM-derived Etv2:GFP+ cells as they migrate towards the midline (Figure 1E, Supplementary Movie S1). These results indicate that there is a rare population of ECs that arise in sequential fashion starting at somite 12.

In mouse and chicken, SDECs emerge from the same region as skeletal muscle progenitor cells, in the dermomyotome compartment (Tozer et al., 2007). To examine the spatial origins of SDECs in the zebrafish, we performed double fluorescent in situ hybridization (FISH) for the endothelial marker etv2 and the skeletal muscle progenitor marker pax3a (Relaix et al., 2005) between $12-14$ ss, where we observed etv2 ${ }^{+}$cells to co-localize with pax3a+ cells in the somite (Figure 1F). However, FISH for etv2 and myod, a marker of differentiated muscle cell types (reviewed in Hernandez-Hernandez et al., 2017), did not show co-localization (Figure 1G). Together, these results suggest that SDECs emerge within the somite from precursor cells shared with the muscle lineage. Because somitic Etv2 ${ }^{+}$cells are localized specifically within the dermomyotome region, the muscle progenitor cell compartment of the somite, a conserved mechanism of SDEC 
generation may be shared among vertebrates (Pouget et al., 2006 ; Mayeuf-Louchart et al., 2014; Mayeuf-Louchart et al., 2016).

\section{The Dermomyotome Contains Progenitors with Muscle and Endothelial Potential}

Since our results above suggested the presence of bipotent progenitors with competence for muscle and endothelial cell differentiation, we sought to determine if blocking skeletal muscle differentiation may lead to enhanced SDEC generation by knocking down mesenchyme homeobox 1 (meox1), an important regulator of muscle cell formation (Mankoo et al., 2003). Using a meox1 translation blocking morpholino (MO) (Nguyen et al., 2014) and FISH, we observed ectopic formation of etv2, meox1 double positive cells in morphant animals (Figure 2A-F). Like normal SDECs, these ectopic SDECs began emerging between 12-16 ss; however, meox1 morphants continued to generate SDECs as late as 26 ss (Figure 2G, H), which we have never observed in wild type animals. Therefore, Meox1 loss of function leads to enhanced and prolonged production of SDECs.

Previous work in mouse identified the Notch signaling pathway as a positive regulator of EC over muscle fate in the somite (Mayeuf-Louchart et al., 2014). We tested the requirement for Notch signaling in zebrafish SDEC generation by knocking down the essential Notch regulator mindbomb (mib) (Itoh et al., 2003) in Etv2:GFP+ animals and examining SDEC formation between 12-14 ss. While loss of Meox1 alone led to ectopic formation of a few SDECs (Figure 2I, J), double knockdown of mib and meox1 led to a profound expansion of Etv2:GFP+ cells within the somite (Figure $2 \mathrm{~K}$ ). These results led us to hypothesize that Notch signaling is dispensable for Etv2:GFP+ cell formation but required for skeletal muscle progenitor maintenance. To examine the role of Notch signaling more precisely in these cells, next we queried Notch $3^{-/-}$animals, since it is the primary Notch receptor in the somites at this stage (Kim et al., 2014). We injected Meox1 MO into Notch3\%-/ embryos and performed FISH for meox1 and etv2 (Figure 2L-N). Using

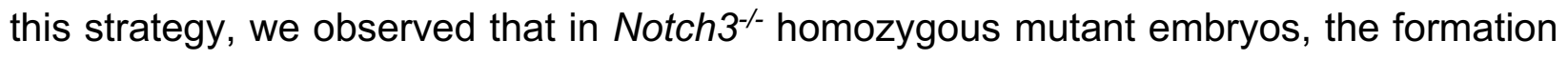
of SDECs was not impaired (Figure 2L, M). Moreover, following combined loss of Notch3 and Meox1, we observed the ectopic formation of etv $2^{+}, \operatorname{meox} 1^{+}$double positive cells by 
FISH (Figure 2N and Supplementary Figure 1). Together, these results show that Notch signaling is dispensable for the specification of SDECs.

To determine which cell populations were specifically affected by loss of Notch3, we assessed the expression levels of markers for muscle progenitors (pax3a, pax $7 b$ ), differentiated muscle cells (myod, myog) and differentiated endothelial cells (evt2, fli1a) by qRT-PCR in Notch3\%- embryos at 24hpf (Figure 20). In Notch3 ${ }^{-/-}$animals, we observed a decrease in expression of the muscle progenitor markers, concomitant with an increase in the expression of muscle differentiation markers and endothelial differentiation markers (Figure 20). Furthermore, we observed premature expression of the muscle differentiation marker MyoHII (Sjoblom et al., 2008; Beier et al., 2011; Salucci et al., 2015) by antibody staining at $48 \mathrm{hpf}$ in Notch $3^{-/-}$animals (Figure $2 \mathrm{P}, \mathrm{Q}$ ). Together, these results indicate that Notch3 signaling is required for $\mathrm{Pax}^{+}, \mathrm{Pax}^{+}$muscle progenitor maintenance, and its absence leads to premature differentiation of muscle and SDEC fates (Figure 2R).

\section{NPAS4I is Required for the Formation of SDECs}

NPAS4I (cloche) is regarded as the most upstream gene required for blood and EC specification (Stainier et al., 1995, Reischauer et al., 2016). We therefore sought to determine if NPAS4I is required for the development of SDECs. WISH at 12 ss embryos showed a complete absence of etv2 expression along the embryonic A-P axis in cloche mutants compared to controls (Figure 3A-B), showing that NPAS4I function is required for both PLM-derived ECs and SDECs. As above, we knocked down the function of meox1 in order to increase SDEC differentiation from bipotent somitic progenitors. SDECs were not observed in this scenario either, indicating NPAS4I function is necessary to generate the SDEC lineage (Figure 3C-D). To further increase the number of SDECs, we injected embryos from Etv2:GFP ${ }^{+/+}$; cloche ${ }^{-/+}$adult pairs with mib Mo and meox1 MO. Similarly, we observed a complete absence of Etv2:GFP+ cells in cloche ${ }^{-/-}$mutant embryos, compared to cloche control siblings (cloche ${ }^{-/+}$, cloche ${ }^{+/+}$) Figure $3 \mathrm{E}-\mathrm{H}$. Moreover, we performed FISH for meox1 and etv2 and did not observe any double positive cells in cloche ${ }^{-/-}$mutants, compared to cloche control embryos (Figure 3I-N). Lastly, we performed qRT-PCR for endothelial and muscle cell genes from 48 hpf cloche- 
I- mutant embryos compared to control cloche control embryos (Figure 30). As expected, there was a decrease in the expression of the endothelial genes etv2 and fli1a. Interestingly, however, we also observed a concomitant increase in expression of skeletal muscle differentiation genes myod and myogenin (Figure 30). Together, these results confirm that NPAS4I (cloche) is required for the specification of endothelial cells from the PLM and establish a similar requirement for SDEC generation from shared skeletal muscle progenitor cells (Figure $3 \mathrm{P}, \mathrm{Q}$ ).

\section{Wnt Signaling Regionalizes the Formation of SDECs}

Previous work has shown that Wnt signaling is required for the differentiation of muscle cells, through activation of the required skeletal muscle factor Myf5 reviewed in ((von Maltzahn et al., 2012)). In addition, inhibition of Wnt signaling in early PM leads to an increase in endothelial cells that can integrate into the zebrafish vasculature (Veldman et al., 2013), suggesting that Wnt signaling may also act later in the somite to balance muscle and endothelial cell production from shared muscle progenitor cells. To confirm that Wnt signaling is active in meox $1^{+}$muscle progenitor cells during SDEC development, we performed FISH for meox1 in the background of a destabilized Wnt/TCF GFP-reporter line (Moro et al., 2012). We observed cells positive for both GFP and meox1 (Figure 4A), indicating that Wnt signaling is active while SDEC fate decisions are occurring. Next, to determine if Wnt inhibition affects SDEC development, we treated etv2:GFP+ embryos with IWP-L6, a potent inhibitor of Wnt protein secretion (Wang et al., 2013), from 2-12 ss. Inhibition of the Wnt signal was confirmed by qRT-PCR for the canonical target gene axin2 (Figure 4B), which led to a decrease in meox1 and an increase in etv2 transcripts. By examining serial sections, Wnt inhibition led to the formation of ectopic Etv2:GFP+ cells in the somites (Figure 4C, D), which we confirmed by performing time-lapse imaging of the same experimental setup between 10 ss and 14 ss (Supplementary Movie S2). Finally, we also confirmed that Wnt signaling is required for meox1 expression (Figure 4E-F'). Together, these results show that Wnt signaling regionalizes the formation of SDECs within the somite within the most lateral region, and that its inhibition results in the ectopic formation of Etv2:GFP+ SDECs. 


\section{SDECs Integrate into the Dorsal Aorta but do not Generate HSPCs}

Next, we were interested in understanding the contribution of SDECs to the developing zebrafish vasculature. To this end we obtained a PM-specific Gal4 transgenic line, Tbx6:Gal4, which has been shown to recapitulate tbx6 mRNA expression (Yabe et al., 2016). We crossed this line to UAS:CRE, which expresses the Cre recombinase upon Gal4 induction only within the PM, and to a ubiquitously expressed reporter line $\beta$ Actin: $>B F P>d s R e d$, which upon genetic recombination switches from a BFP to dsRed expression cassette (abbreviated as $\mathrm{A} 2 \mathrm{BD}$ ) for clarity. Upon confocal imaging of the triple transgenic tbx6:Gal4; UAS:Cre; $A 2 B D$ animals at 48hpf, we observed dsRed+ cells within the region of the axial vasculature (Figure $5 \mathrm{~A}-\mathrm{C}$ ). To further confirm that these cells were ECs that arise from a Tbx6+ somitic population, we crossed the Tbx6:Gal4; UAS:Cre line with a previously published vascular-specific switch line, Kdrl:CSY (Zhou et al., 2011) The latter transgene is driven by an endothelial-specific promoter, and upon Cre-induced recombination switches ECs from CFP to YFP expression. When we imaged the different portions of the DA (Figure 5D) in Tbx6:Gal4; UAS:Cre; Kdrl:CSY triple transgenic embryos via confocal microscopy at 4 days post fertilization (dpf), we observed YFP+ cells that localized preferentially to the anterior region of the dorsal aorta (Figure 5E-G, $\mathrm{K}$, Supplementary Figure 2). Notably, the most anterior region of the DA contained a higher percentage of YFP+ cells (Figure 5E, K), with the contribution of YFP+ cells decreasing in an anterior to posterior manner (Figure 5G, C). We found this labeling pattern to be consistent among different embryos over a range of developmental time points.

To complement these results, we performed lineage tracing using a LPM-specific switch line, Draculin-CreERT2 (Henninger et al., 2017), likewise crossing it to Kdrl:CSY for EC-specific reporting. We incubated embryos with tamoxifen (4-OHT) to induce Crebased recombination between 8 and 24 hpf. Confocal imaging showed complementary results to those from our PM-specific Tbx6+ experiments (Figure $5 \mathrm{H}, \mathrm{J}$ ). We observed that Draculin-derived YFP+ cells contribute to all regions of the vasculature, as would be expected from an LPM source. However, we observed the contribution of these cells was more robust within the posterior region of the DA compared with the Tbx6-labelled 
SDECs, consistent with our PM lineage tracing data (Figure 5E, K). Together, these results demonstrate that SDECs integrate into the DA in zebrafish and appear to contribute preferentially to the anterior portion of the dorsal aorta.

Since HSPCs derive from hemogenic endothelium specifically within the DA, we examined whether or not SDECs can generate HSPCs. We lineage traced PM-derived cells into the kidney, the adult hematopoietic organ in teleosts. We dissected kidneys of adult Tbx6:Gal4; UAS:Cre; $A 2 B D$ transgenic animals and observed no contribution of switched dsRed+ cells to any hematopoietic lineages at this stage (Figure 5D). As a positive control for hemogenic endothelium, a ubiquitous vascular-specific transgenic Cre driver was utilized, Kdrl-Cre; A2BD (Supplementary Figure 3). Taken together, these results demonstrate that SDECs integrate into the dorsal aorta but do not generate HSPCs.

\section{Molecular Differences in ECs Foster Cellular Diversity within the Vasculature}

The discovery of SDECs in zebrafish prompted us to revisit EC diversity in the developing zebrafish embryo using single cell RNA sequencing (scRNAseq). To do so, we collected EC enriched samples from distinct vascular transgenic animals, with the idea of representing diverse endothelial cohorts. Specifically, we purified cells via fluorescenceactivated cell sorting (FACS) from Etv2:kaede, Fli1:dsRed; Tp1:GFP, and Draculin:Dendra:H2B between 22-24 hpf from synchronized embryos and we performed scRNAseq on each sample. Following quality control (QC) and basic clustering of each sample, we merged individual datasets. Altogether, we obtained a total of 10,160 single cells, 2,996 cells of which belonged to the endothelial lineage. Via unsupervised clustering of single cell transcriptomes and based upon known lineage associations, we identified six distinct endothelial cells clusters (Figure 6A). Using known genes within established lineages, we named each cluster based on likely tissue origins (Supplementary Sheet1). First, we identified an endothelial cell cluster 1 that contained the expression of paraxial mesoderm (PM) signatures genes, including fras $1, f n 1 b, f b n 2 b$, acta1a and fgf8a. This PM signature suggested this population to represent SDECs. Cluster 2 (Endocardium) likely represents endocardial ECs based upon co-expression of canonical heart genes, including gata5, hand2 and tbx20. Cluster 3 (Kidney vascular 
endothelium cells, KVECs) co-expressed kidney-associated genes, such as pax2a, pax $2 b$, jag2b, and osr1. Cluster 4 (Brain vascular endothelium cells, BVECs) coexpressed brain-associated genes, including tbx1 and eya1. Finally, we identified a large endothelial cluster 5 (General endothelium) that co-expressed canonical endothelial genes as well as a likely hemogenic cluster directly adjacent to it that co-expressed endothelial and hematopoietic genes, including as gfi1aa, myb and cebpa. Therefore, we merged clusters 6-7 that were adjacent to the General endothelium cluster, and we termed it hemogenic endothelium. Differential expression analysis among clusters identified distinct gene programs enriched within specific subsets (Figure 6B, Supplementary Sheet1). Thus, this scRNA-seq approach served to not only identify SDECs and hemogenic endothelium, but also a variety of additional tissue-specific EC subsets in the 22-24 hpf embryo.

\section{SDECs Support the Emergence of HSPCs}

Differential expression analysis of SDECs versus other endothelial clusters identified many genes previously attributed to 'niche' functions required for the induction of aortic hemogenic endothelium (Figure 7A) (Charbord et al., 2014). Notable among these is BMP4, which is required for the induction and maintenance of Runx1 expression within the hemogenic endothelium (Wilkinson et al., 2009). These results suggested that SDECs might be acting in a paracrine manner to support hematopoietic induction. If so, we reasoned that changes in the number of SDECs may result in altered formation of hematopoietic cells. Increasing the numbers of SDECs via enforced expression of etv2 with a muscle-specific mylz2 promoter (Ju et al., 2003), or knockdown of meox1, led to an increase in runx1+ expression by WISH (Figure 7B-E). By contrast, decreasing the number of SDECs via over expression of meox $1 \mathrm{mRNA}$ led to the loss of $r u n \times 1^{+}$and gata $2 b^{+}$hematopoietic cells in the DA (Figure 7F-I). Next, since bmp4 expression appeared to be differentially regulated between SDECs and ECs of the PLM (Figure7A), we queried if its expression would be increased upon increase generation of SDECs. Upon loss of meox1 function, we found that bmp4 expression was increased by WISH at 24hpf in the DA (Figure 7J, K). Taken together, these results demonstrate that SDECs 
act in a paracrine manner through BMP signaling to support the induction of hematopoietic cells from neighboring hemogenic endothelial cells.

\section{Early Notch Signaling Regulates the Rate of Differentiation of Endothelial Cells}

Our results thus far have shown that SDECs integrate exclusively to the dorsal aorta, act in a paracrine manner to support the formation of hematopoietic cells, and do not give rise to HSPCs. With the noted importance of Notch signaling in establishment of both arterial and hemogenic endothelium, we were interested in exploring how Notch signaling might affect the formation of SDECs, arterial cells and hematopoietic cells at the single cell level. Previous work has shown that global inhibition of Notch signaling leads to loss of arterial cell fate and hemogenic endothelium (Lawson et al., 2001) (Burns et al., 2005). Conversely, Notch overexpression results in the expansion of the hematopoietic program (Guiu et al., 2013). The exact molecular changes that occur following Notch modulation between hemogenic and arterial endothelium are difficult to assess since each population is closely related and the number of cells in the developing embryo are limited. We thus utilized scRNAseq to profile single Etv2:Kaede ${ }^{+}$cells from $22 \mathrm{hpf} \mathrm{mib}^{-/-}$or control $\left(\mathrm{mib}^{-/+}\right.$ and $\mathrm{mib}^{+/+}$) sibling mutant embryos, which have global loss of Notch signaling. From control siblings, we FACS purified 2,817 single cells, 1,392 of which belong to the endothelial lineage. Similarly, in the Notch mutant, we purified 2,720 single cells, 1,008 cells of which belong to the endothelial lineage. Comparison of Notch mutants to control sibling cells identified 155 genes to be differentially expressed (Supplementary Sheet2). Figure 8A shows a heatmap of the 20 most upregulated and downregulated genes between mib mutant and control cells. Interestingly, arterial genes in Etv2:kaede+, mib-/ mutant cells were expressed at $22 \mathrm{hpf}$ (Figure $8 \mathrm{H}$ ). This result was unexpected, since Notch signaling has been thought to be required for the establishment of the arterial cell program. Because mRNA abundance in RNAseq data only captures a static snapshot at a specific point in time, we decided to utilize RNA velocity techniques (Zywitza et al., 2018 ) to gauge the differentiation states of $\mathrm{mib}^{-/-}$or control ECs.

RNA velocity uses the time derivative of gene expression state by estimating spliced versus unspliced mRNA from common RNA sequencing protocols. As an output, it generates high dimensional vectors that predict the future state of individual cells on a 
timescale of hours. During a dynamic process, such as a cell entering a differentiation program, an increase in the transcription rate alpha results in a rapid increase of unspliced mRNA, which is then followed by an increase in spliced mRNA, until a new steady state is reached (Figure 8B-E). Using RNA Velocity, we generated high dimensional vectors of Etv2:Kaede+ EC cell states (Figure 8F, G), as well as individual phase portraits (Figure $8 \mathrm{H}$ ) for arterial genes. These results show that the induction of endothelial differentiation genes follow a pattern across the endothelial cell manifold. For example, we observe the arterial transcripts $d I l 4$, hey2 and ephb2a to be induced at the periphery of ECs (cells with longer arrows) and are thus farther away in the differentiation hierarchy from ECs located within the medial portion of the cluster (shorter arrows) (Figure 8F).

To determine the consequences in the absence of Notch signaling in Etv2:Kaede ${ }^{+}$, $\mathrm{mib}^{-/}$ECs, we performed similar RNA velocity analysis. First, we observed that the directional flow of general ECs in Notch mutant endothelium to be more dynamic (Figure 8G; longer arrows) than control ECs (Figure 8F). These data suggest that Notch mutant ECs are further along the differentiation hierarchy than control Etv2:Kaede ${ }^{+} \mathrm{ECs}$. Upon closer inspection of the arterial differentiation gene program, we observe that arterial genes are prematurely expressed in Notch mutant $\mathrm{mib}^{-/-}$when compared to control Etv2:Kaede ${ }^{+}$ECs (Figure 8H) . By comparing spliced and unspliced arterial genes, we noticed an expression hierarchy of $d l 14$, hey2 and efnb2a, respectively (Figure $8 \mathrm{H}$ ). These results show that early Notch signaling is dispensable for the initiation of the aortic program but is required for the regulation of endothelial precursors entering its differentiation program. Thus, the early role of Notch signaling may be to maintain EC precursors in a plastic, or primed state.

Next, we were interested in assessing the difference in the hemogenic endothelium and pre-HSPC clusters of controls versus $\mathrm{mib}^{-/-}$; Etv2:Kaede ${ }^{+}$cells. We computationally

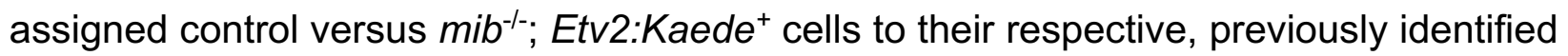
clusters. We observed that hemogenic-like cells (hemogenic endothelium and preHSPCs) still mapped within the population of mib-/-; Etv2:Kaede ${ }^{+}$cells. However, we noticed that their numbers were significantly reduced in Notch mutant ECs, 166 cells in control vs 77 cells in $\mathrm{mib}^{-/}$. In addition, specific comparison of the Pre-HSPC clusters showed that genes important for hematopoietic cell formation such as Imo2 and gpr182 
were reduced in $\mathrm{mib}^{-/-}$mutant cells (Supplementary Figure 4). Lastly, we compared the gene expression of SDECs between control versus mib-/- Etv2:Kaede ${ }^{+}$cells and did not observe a significant change in the SDEC gene program (Supplementary Figure 5). Together, these results suggest that Notch signaling plays a more central role in the specification of hemogenic endothelium rather than in the arterial or SDEC program itself.

\section{Inhibitor of Differentiation 1 (ID1) Works in Tandem with Notch Signaling to Enable the Specification of the Hemogenic Endothelium}

One of the most highly differentially expressed genes arising from the Notch mutant single-cell analysis was Inhibitor of Differentiation 1 (ID1) (Figure 9A). As noted above, the RNA velocity data indicated that Notch signaling may serve as a gatekeeper for differentiation onset of ECs. Previous work has shown that Inhibitor of differentiation genes can maintain progenitors in an undifferentiated state and help facilitate choices between distinct cellular fates (Zhang et al., 2014) (Malaguti et al., 2019) (Leeanansaksiri et al., 2005) (Bedford et al., 2005; Helsel et al., 2017; Jones et al., 2006; Light et al., 2005; Yun et al., 2004). To explore how ID1 and Notch signaling can allow angioblasts to acquire hemogenic endothelial cell fate, we tested the function of ID1 in EC formation, and its interaction with the Notch signaling pathway. In mib-/- mutant embryos, we observed loss of ID1 expression in the endothelium (Figure 9A, B), confirming the results we obtained through scRNA-seq (Figure 8A). Next, we overexpressed NICD in vascular cells using Cdh5:Gal4; UAS-NICD, and observed increased expression of ID1 (Figure 9C, D). Together, these results show that Notch signaling regulates the expression of ID1 in the endothelium. Next, to explore potential roles of ID1 in EC fate specification, we validated an ID1 MO (Supplementary Figure 6) and used it to block ID1 gene function. Upon ID1 knockdown, we observe that the expression of endothelial genes cdh5, notch1b and $t b \times 20$, remained unchanged (Figure $9 \mathrm{E}-\mathrm{J}$ ). However, expression of runx 1 , the key marker of commitment to hemogenic endothelium, was lost (Figure 9K, L). These results show that ID1 is an important regulator of hemogenic cell fate. Next, we were interested in determining the genetic interactions between ID1 and Notch Signaling in the specification of the hemogenic endothelium (Figure 9M-T). Enforced expression of NICD in the vasculature of ID1 morphants embryos failed to rescue runx1 expression in the 
hemogenic endothelium (Figure 9M-P). Conversely, enforced expression of ID1 via mRNA injection into mib/- mutant embryos, similarly showed that ID1 gene function is insufficient to rescue loss of Notch signaling in the hemogenic program (Figure 9Q-T). Together, these results demonstrate that ID1 and Notch signaling act in tandem to specify HSPC precursors, likely by maintaining angioblasts in a plastic state to receive the additional cues necessary for acquisition of hemogenic endothelium cell fate.

\section{Discussion}

Here, we present an extensive analysis on how a bipotent skeletal muscle progenitor population gives rise to a contingent of endothelial cells that is functionally distinct from endothelial cells specified in the LPM. Through single cell analysis we identify unique molecular signatures sufficient to identify somite derived endothelial cells (SDECs), brain endothelial cells (ECs), kidney ECs and endocardium by 24hpf. Together, these results indicate that cell fate restriction of EC subsets occurs earlier than previously thought. Our analysis of endothelial cells at the single cell level suggests that Notch signaling is dispensable for the acquisition of arterial cell fate but is required for the specification of hemogenic endothelium. In addition, our findings elucidate how Notch signaling works together with inhibitor of differentiation 1 (ID1) to properly maintain a progenitor state that allows for the acquisition of hemogenic endothelial fate. Subsequently, SDECs acts as a secondary molecular input to the hemogenic program that is required for the formation of HSPCs.

Avian and murine studies have previously identified a population of endothelial cells that arise from the somites (Ambler et al., 2001; Esner et al., 2006; Kardon et al., 2002; Mayeuf-Louchart et al., 2014; Mayeuf-Louchart et al., 2016; Pardanaud et al., 1996; Pouget et al., 2006; Wilting et al., 1995; Yvernogeau et al., 2012). In zebrafish, it has been thought that all endothelial and blood cells arise exclusively from the LPM (Childs et al., 2002; Lawson and Weinstein, 2002; Jin et al., 2005; Zhang and Rodaway, 2007; Kohli et al., 2013). Furthermore, angioblasts are thought to be specified as an equipotent population that only upon migration to the midline, undergo progressive cell-fate restriction (Lawson et al., 2001; Kobayashi et al., 2014). To our knowledge there have only been two studies in zebrafish that have shown that the paraxial mesoderm can 
generate endothelial cells (Martin and Kimelman, 2012; Nguyen et al., 2014). The first noted that presomitic mesoderm could generate ECs that incorporated into caudal blood vessels following inhibition of the Wnt signaling pathway after gastrulation (Martin and Kimelman, 2012). The second noted a rare population of ECs generated in the somite from a central location termed the "endotome" that migrated to the developing dorsal aorta (Nguyen et al., 2014). Each of these studies was based on retrospective analyses, however, making it difficult to ascertain precisely when and where SDECs arise, and their extent of contribution. Use of an Etv2:GFP transgene, one of the earliest markers of endothelial cell fate acquisition, allows precise visualization of when and where SDECs emerge from the somites. Furthermore, via use of an endothelial-specific switch transgene ,ECs from either the LPM or PM can be permanently and differentially marked to follow their respective contributions to the vasculature. Similar indelible lineage tracing approaches allowed us to rule out any contribution of SDECs to the adult hematopoietic tissue, which is consistent with many previous studies concluding that the adult hematopoietic program is LPM-derived(Henninger et al., 2017; Jin et al., 2007; Murayama et al., 2006). These results are consistent with a previous study from Currie and colleagues that identified a rare population of EC precursors born in the somite that incorporated into the axial vessels but did not appear to generate blood. Their results suggested a central location within the somite that generated ECs, which they termed the "endotome". In our study, we observed that somite-derived Etv2+ ECs arise from the hypaxial dermomyotome, consistent with earlier observations in avian and mouse embryos (Eichmann et al., 1993; Ema et al., 2006; Pouget et al., 2006; Tozer et al., 2007). We observed no ECs from central locations within the somite. Notably, the hypaxial dermomyotome is comprised of bipotent-skeletal muscle progenitors that upon local cues generate ECs or myoblasts. Since these bipotent progenitors are present in the territory where the hypaxial muscle precursors originate (Christ and Ordahl, 1995), we believe a more appropriate term for this somitic compartment would be the 'Myo-Endotome'.

We observe that Etv2 ${ }^{+}$SDECs emerge starting at the 12-somite stage, concomitant with the epithelization of the somite and the migration of LPM-derived ECs to the midline. Previous work in mouse had suggested that Notch signaling promotes the specification of SDECs at the expense of muscle cell fates (Mayeuf-Louchart et al., 2014). 
By contrast, we find that Notch signaling is essential for the maintenance of muscle progenitors, as previously shown in mice (Schuster-Gossler et al., 2007). Loss of the Notch signaling components Mib or Notch3 results in a premature depletion of skeletal muscle progenitor markers, and a concomitant increase of differentiated muscle and endothelial cell genes. Therefore, our results show that Notch signaling is required for the maintenance of muscle progenitors and not the cell fate choice between muscle and endothelium. In addition, we find Wnt signaling to be a necessary factor in the regionalization of muscle and endothelial cells within the somites, in agreement with previous work (Borello et al., 2006; Martin and Kimelman, 2012). We find that during homeostasis, few Etv2:GFP ${ }^{+}$SDECs delaminate from the hypaxial dermomyotome starting from somite number 12. However, combined loss of Notch signaling and Meox1 shows that EC competence within the somite encompasses a much larger territory, extending as far as the median dermomyotome (Supplementary Figure 1). Interestingly, we find that endothelial potential within bipotent skeletal muscle progenitors is NPAS4Idependent. These results are surprising, since NPAS4I has been shown to be the earliest gene required for EC specification and was thought to be restricted to the LPM starting at the tailbud stage (Reischauer et al., 2016). Furthermore, expression of NPAS4I decreases sharply during early somitogenesis. Together, these results suggest that NPAS4I may provide endothelial competence to an early mesodermal precursor, or may act in a non-cell autonomous manner. Future work should help clarify the exact function of NPAS4I and its activity across mesodermal derivatives.

Our single-cell analyses identified an endothelial population with PM gene signatures that we believe are indicative of SDECs. Our work also classified distinct endothelial clusters at 22-24hpf that exhibit unique molecular signatures that correspond to brain endothelium, kidney endothelium, and endocardium. Interestingly, our results also suggest that SDECs emerge from shared muscle progenitors that arise from the lateral region of the PM that diverges from LPM progenitors by mid-gastrulation (GarciaMartinez and Schoenwolf, 1992; Schoenwolf et al., 1992; Selleck and Stern, 1991; Psychoyos and Stern, 1996). Future work should help determine if distinct regions within the mesoderm can give rise to functionally divergent subsets of angioblasts. Plasticity of EC development is further illustrated from recent work that surprisingly showed that 
extraembryonic derived erythomyeloid progenitors can give rise to up to $60 \%$ of liver ECs in mice (Plein et al., 2018).

Our single cell analysis of Notch mutant mib - $^{-/}$Etv2:Kaede ${ }^{+}$ECs provides interesting insights into the role of Notch signaling in early endothelial specification. Using RNA Velocity, our results indicate that endothelial cells at $22 \mathrm{hpf}$ are at distinct states along their differentiation hierarchy. Interestingly, when we compare wt Etv2:Kaede ${ }^{+}$ single cells to those from $\mathrm{mib}^{-/-}$; Etv2:Kaede ${ }^{+}$mutants, we find cells further along the differentiation hierarchy in the absence of Notch signaling. Consistent with this finding, we observe transcripts of the arterial gene program to be prematurely expressed. Our results thus highlight a previously underappreciated role for Notch signaling in maintaining angioblasts in a plastic state to regulate their rate of differentiation. Furthermore, our results suggest that early Notch signaling is dispensable for the initiation of the arterial gene program, in agreement with previous studies (Casie Chetty et al., 2017; Wythe et al., 2013), and for the specification of SDECs. Moreover, our single cell analyses mapped Notch mutant Etv2:Kaede ${ }^{+}$cells to the hemogenic cluster in 22 hpf embryos, which allowed us to investigate the consequences of loss of Notch signaling in hemogenic progenitors. Absence of Notch signaling is associated with a reduction of expression of key hematopoietic genes, including gfi1aa, runx1, and gata2b. Since we are still able to map $\mathrm{mib}^{-/-}$mutant cells to the hemogenic cluster, this suggests that additional signal(s) acting in concert with Notch are necessary for the correct specification of hemogenic endothelium. Together, our results support the idea that Notch signaling is required for maintaining endothelial progenitors in a plastic state that is required for the proper transition and differentiation towards hemogenic endothelium.

This role for Notch signaling in facilitating the transition to hemogenic endothelium is further illustrated by the role of ID1, one of the most differentially expressed genes between wt and Notch mutant Etv2-kaede ${ }^{+}$cells. We found Notch signaling to act upstream of ID1 function, and both signaling pathways to be required for the proper specification of hemogenic endothelium. These results suggest that the precursors of hemogenic endothelium need to be maintained in a progenitor state by both Notch and ID1 activity. Once these precursors incorporate into the nascent dorsal aorta, their transition to HSPCs is instructed via HSPCs. Previous work has suggested that the 
mesenchyme, located directly underneath the dorsal aorta, is a source of BMP ligand necessary for the HSC emergence (Crisan et al., 2015; Durand et al., 2007; Lempereur et al., 2018; Pouget et al., 2014; Wilkinson et al., 2009). More recent studies have also elucidated a role for non-hemogenic ECs in supporting the hemogenic program and in amplifying HSPC number (Butler et al., 2012; Butler et al., 2010; Butler and Rafii, 2012; Gori et al., 2015; Gori et al., 2017; Guo et al., 2017; Hadland et al., 2015; Kim et al., 2014; Kobayashi et al., 2010; Lis et al., 2017; Raynaud et al., 2013; Sandler et al., 2014). Interestingly, several groups have successfully differentiated endothelial precursors into transplantable HSPCs, a process that requires an endothelial 'niche' population (Lis et al., 2017; Sandler et al., 2014). Our work indicates that a similar process occurs in vivo, where SDECs are required for the induction of hematopoietic cell formation. Future work will elucidate the molecular nature of this requirement and will forward efforts to instruct HSPC fate from human pluripotent precursors.

\section{Materials and Methods}

Zebrafish husbandry

Wild-type $\mathrm{AB}^{*}$ and transgenic TgBAC(kdrl:LOXP-AmCyan-LOXP-ZsYellow) (Zhou et al., 2011) referred to as Kdrl:CSY; Tg(etv2.1:EGFP)zf372 (Veldman and Lin, 2012) referred to as Etv2:GFP; Tg(Tbx6:Gal4FF:GFPnls) (Yabe et al., 2016) referred to as Tbx6:Gal4; TgBAC(etv2:Kaede)ci6 (Kohli et al., 2013) referred to as Etv2:Kaede, Tg(5xUAS-E1B:6xMYC-notch1a) (Scheer et al., 2001) referred to as UAS:NICD; mib ${ }^{\text {ta52b/ta52b }}$ (Itoh et al., 2003) referred to as mib-/-; Notch3 ${ }^{\text {fh332/fh332 (Alunni et }}$

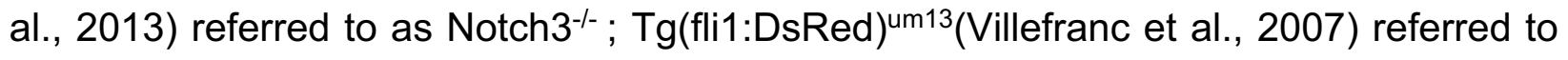
as fli1:DsRed; Tg(Tp1:GFP)um14 (Parsons et al., 2009) referred to as Tp1:GFP, Et(ph1bd1:Gal4-mcherry) (Distel et al., 2009) referred to as ph1bd1:Gal4, Tg(cdh5 ${ }^{\text {BAC: }: g a l 4 f f)}{ }^{m u 101}$ (Bussmann and Schulte-Merker, 2011) referred to as cdh5:Gal4; Tg(Drl:H2Bdendra) (Mosimann et al., 2015) referred to as Drl:H2Bdendra; Tg(Drl:CreERT) (Henninger et al., 2017) referred to as Drl:CreERT; Tg(UAS-Cre)* (Butko et al., 2015) referred to as UAS-Cre. zebrafish embryos and adult fish were raised in a circulating aquarium system (Aquaneering) at $28^{\circ} \mathrm{C}$ and maintained in accordance with UCSD Institutional Animal Care and Use Committee (IACUC) guidelines. *Of note, 
$\operatorname{Tg}$ (UAS-CRE) transgene animals were not kept in the background of any $\mathrm{Tg}(\mathrm{Gal} 4)$ transgenic animals, since we noticed it promoted the silencing of the $\mathrm{Tg}$ (UAS-CRE) transgene in the next generation.

\section{WISH}

Whole-mount single or double enzymatic in situ hybridization was performed on embryos fixed overnight with $4 \%$ paraformaldehyde (PFA) in phosphate buffered saline (PBS). Fixed embryos were washed briefly in PBS and transferred into methanol for storage at $-20^{\circ} \mathrm{C}$. Embryos were rehydrated stepwise through methanol in PBS-0.1\% Tween 20 (PBT). Rehydrated embryo samples were then incubated with $10 \mu \mathrm{g} \mathrm{ml}^{-1}$ proteinase $\mathrm{K}$ in PBT for $5 \mathrm{~min}$ for 5 to 10 somite stage (12-15 hpf) embryos and $15 \mathrm{~min}$ for 24 to $36 \mathrm{hpf}$ embryos. After proteinase $\mathrm{K}$ treatment, samples were washed in PBT and refixed in $4 \%$ PFA for 20 min at room temperature. After washes in two changes of PBT, embryos were prehybridized at $65{ }^{\circ} \mathrm{C}$ for $1 \mathrm{~h}$ in hybridization buffer $(50 \%$ formamide, $5 \mathrm{x}$ SSC, $500 \mu \mathrm{g} \mathrm{ml}^{-1}$ torula tRNA, $50 \mu \mathrm{g} \mathrm{ml}^{-1}$ heparin, $0.1 \%$ Tween $20,9 \mathrm{mM}$ citric acid (pH 6.5)). Samples were then hybridized overnight in hybridization buffer including digoxigenin (DIG)- or fluorescein-labelled RNA probe. After hybridization, experimental samples were washed stepwise at $65^{\circ} \mathrm{C}$ for 15 min each in hybridization buffer in $2 \times$ SSC mix $(75 \%$, $50 \%, 25 \%$ ), followed by two washes with $0.2 \times$ SSC for 30 min each at $65^{\circ} \mathrm{C}$. Further washes were performed at room temperature for 5 min each with $0.2 \times$ SSC in PBT $(75 \%$, $50 \%, 25 \%$ ). Samples were incubated in PBT with $2 \%$ heat-inactivated goat serum and $2 \mathrm{mg} \mathrm{ml}^{-1}$ bovine serum albumin (block solution) for $1 \mathrm{~h}$ and then incubated overnight at $4{ }^{\circ} \mathrm{C}$ in block solution with diluted DIG-antibodies $(1: 5,000)$ conjugated with alkaline phosphatase (AP) (Roche). To visualize WISH signal, samples were washed three times in AP reaction buffer (100 mM Tris, $\mathrm{pH} 9.5,50 \mathrm{mM} \mathrm{MgCl}_{2}, 100 \mathrm{mM} \mathrm{NaCl}$, and $0.1 \%$ Tween 20) for 5 min each and then incubated in the AP reaction buffer with NBT/BCIP substrate (Roche).

For two-color double FISH, embryos were blocked in maleic acid buffer (MAB; $150 \mathrm{mM}$ maleic acid, $100 \mathrm{mM} \mathrm{NaCl}, \mathrm{pH} 7.5$ ) with $2 \%$ Roche blocking reagent (MABB) for $1 \mathrm{~h}$ at 
room temperature, after hybridizing at $65^{\circ} \mathrm{C}$ with probes as described above. Embryos were incubated overnight at $4^{\circ} \mathrm{C}$ in MABB with anti-fluorescein POD (Roche) at a 1:500 dilution. After four washes in MAB for 20 min each followed by washes in PBS at room temperature, embryo samples were incubated in TSA Plus Fluorescein Solution (Perkin Elmer) for $1 \mathrm{~h}$. Embryos were washed 10 min each in methanol in PBS (25\%, 50\%, 75\%, $100 \%$ ). Embryos were incubated in $1 \% \mathrm{H}_{2} \mathrm{O}_{2}$ in methanol for $30 \mathrm{~min}$ at room temperature and washed for 10 min each in methanol in PBS (75\%, 50\% 25\%) and 10 min in PBS. After blocking for $1 \mathrm{~h}$ in MABB, embryos were incubated overnight at $4{ }^{\circ} \mathrm{C}$ in MABB with anti-DIG POD (Roche) at a 1:1,000 dilution. Samples were washed and incubated in TSA Plus CY3 solution (Perkin Elmer) as described above. Embryos were washed three times for 10 min each in PBT and refixed in 4\% PFA after the staining was complete. Antisense RNA probes for the following genes were prepared using probes containing DIG or fluorescein labelled UTP: etv2, meox1, tcf15, pax3a, myoD,

\section{Immunofluorescence and microscopy}

For immunofluorescence staining for Myc in hsp70:gal4; UAS:NICD-myc zebrafish embryos after WISH, $100 \%$ acetone was added to the embryos ( 7 min at $-20^{\circ} \mathrm{C}$ ) instead of proteinase $\mathrm{K}$ during the WISH procedure described above. WISH samples of embryos were blocked in MABB for $1 \mathrm{~h}$ and incubated overnight in MABB with anti-Myc monoclonal 9E10 antibodies at 1:100 (Covance). After four washes in MABB for 30 min each, embryos were incubated in AlexaFuor 488 donkey anti-mouse IgG secondary antibodies (ThermoFisher) at 1:500 in MABB. After staining, embryos were washed in MABB for four times for 30 min each. Live transgenic embryos and flat-mount or whole-mount two-colour double FISH samples were imaged using confocal microscopy (SP5 or SP8 Leica ). Embryos were embedded and sectioned as previously described in Kobayashi et al., 2014.

\section{Pharmacological treatment}

IWR (Tocris) was dissolved in DMSO at a concentration of $10 \mathrm{mM}$. Zebrafish $\mathrm{AB}^{*}$ embryos were incubated in $10 \mu \mathrm{M}$ IWR solution from 11 to $15 \mathrm{hpf}$ followed by fixation with $4 \%$ PFA or snap frozen for RNA collection. 


\section{Microinjections of morpholinos, mRNA and plasmids.}

Antisense morpholinos (MOs; Gene Tools, LLC) were diluted as 1- or 3-mM stock in $\mathrm{H}_{2} \mathrm{O}$. Meox1-MO, Mib-MO, and ID1-MO were injected at 1- to 2-cell stage of development. The sequence of translation-blocking targeted ID1-MO1 is $5^{\prime}-3^{\prime}$. Full-length ID1 and mOrange-CAAX mRNAs were synthesized from linearized pCS2+ID1 or mOrangeCAAX with the mMessege mMaching kit (Ambion). ID1 and mOrange-CAAX mRNA were injected with $100 \mathrm{pg}$ into 1- to 2-cell stage embryos. 25pg of Mylz2:Etv2 construct was coinjected with 50pg of Transposase mRNA. All microinjections were performed with the indicated concentration of RNA or MO in a volume of $1 \mathrm{nl}$ using a PM 1,000 cell microinjector (MDI).

\section{FACS}

$\operatorname{Tg}\left(E t v 2: k a e d e ; m^{-/-}\right)$and $\operatorname{Tg}\left(E t v 2: k a e d e ; m^{+/+}\right), \operatorname{Tg}\left(E t v 2: k a e d e ; m^{+/-}\right)$, were separated into two distinct pools at $22 \mathrm{hpf}$ based on their head phenotype as previously described (Bingham et al.). Tg(Fli1:dsRed;Tp1GFP) and Tg(Draculin:Dendra) were separately dissociated in PBS supplemented with $10 \%$ FBS by homogenizing with sterile plastic pestle or pipette. Dissociated cells were filtered through a $35-\mu$ m nylon cell strainer (Falcon 2340) and then rinsed with PBS with 10\% FBS. Propidium iodide (Sigma) was added $\left(1 \mu \mathrm{g} \mathrm{m}^{-1}\right)$ to exclude dead cells and debris. FACS was performed based on GFP, Dendra, and DsRed fluorescence with a FACS Aria II flow cytometer (Beckton Dickinson).

\section{Quantitative real-time RT-PCR}

Total RNA was collected from whole embryos ( 20 embryos) using TRIzol reagent (Ambion, Life Technologies) and isolated from Notch3 ${ }^{-/}$mutant embryos or control siblings at $48 \mathrm{hpf}$; Cloche ${ }^{-/}$mutant embryos or control siblings at $48 \mathrm{hpf}$; or IWP2 treated and control embryos at 15hpf with the RNeasy kit (Qiagen). cDNA was generated from total RNA with iScript cDNA synthesis kit (Bio Rad). The following primers were used for cDNA quantification: ef1 $\alpha$ (forward, 5'- GAGAAGTTCGAGAAGGAAGC -3'; reverse, 5'CGTAGTATTTGCTGGTCTCG -3'), etv2 (forward, 5'- CGAGGTTCTGGTAGGTTTGAG 3'; reverse, 5'- GCACAAAGGTCATGTTCTCAC -3') , fli1a (forward, 5'- 
CGTCAAGCGAGAGTATGACC -3'; reverse, 5'- AGTTCATCTGAGACGCTTCG -3'), myod1 (forward, 5'- GAAGACGGAACAGCTATGAC -3'; reverse, 5'GGAGTCTCTGTGGAAATTCG -3'), myf5 (forward, 5'CCAGACAGTCCAAACAACAGACC -3'; reverse, TGAGCAAGCAGTGTGAGTAAGCG -3'), pax3a (forward, 5'ATTCCTTGGAGGTCTCTACG -3'; reverse, 5'- CTACTATCTTGTGGCGGATG -3'), pax7b (forward, 5'- CAGTATTGACGGCATTCTGGGAG -3'; reverse, 5'TCTCTGCTTTCTCTTGAGCGGC -3'), myf5 (forward, 5'- GAATAGCTACAACTTTGACG -3'; reverse, 5'- GTAAACTGGTCTGTTGTTTG -3'), myog (forward, 5'GTGGACAGCATAACGGGAACAG -3'; reverse, 5'-TCTGAAGGTAACGGTGAGTCGG3').

\section{Single-cell RNA sample preparation}

After FACS, total cell concentration and viability were ascertained using a TC20 Automated Cell Counter (Bio-Rad). Samples were then resuspended in 1XPBS with 10\% BSA at a concentration between 800-3000 per ml. Samples were loaded on the 10X Chromium system and processed as per manufacturer's instructions (10X Genomics). Single cell libraries were prepared as per the manufacturer's instructions using the Single Cell 3' Reagent Kit v2 (10X Genomics). Single cell RNA-seq libraries and barcode amplicons were sequenced on an Illumina HiSeq platform.

\section{Single-cell RNA sequencing analysis}

The Chromium 3' sequencing libraries were generated using Chromium Single Cell 3' Chip kit v3 and sequenced with (actually, I don't know:( what instrument was used?). The Ilumina FASTQ files were used to generate filtered matrices using CellRanger (10X Genomics) with default parameters and imported into $\mathrm{R}$ for exploration and statistical analysis using a Seurat package (La Manno et al., 2018). Counts were normalized according to total expression, multiplied by a scale factor $(10,000)$, and log transformed. For cell cluster identification and visualization, gene expression values were also scaled 
according to highly variable genes after controlling for unwanted variation generated by sample identity. Cell clusters were identified based on UMAP of first 14 principal components of PCA using Seurat's method, Find Clusters, with a original Louvain algorithm and resolution parameter value 0.5. To find cluster marker genes, Seurat's method, FindAIIMarkers. Only genes exhibiting significant (adjusted p-value < 0.05) a minimal average absolute log2-fold change of 0.2 between each of the clusters and the rest of the dataset were considered as differentially expressed. To merge individual datasets and to remove batch effects, Seurat v3 Integration and Label Transfer standard workflow (Stuart et al., 2019).

\section{Plasmid Construction}

Plasmids Expression constructs were generated by standard means using PCR from cDNA libraries generated from zebrafish larvae at $24 \mathrm{hpf}$, these were cloned into pCS2+, downstream of a SP6 promoter. Previously described Mylz2 promoter (Ju et al., 2003) was cloned upstream of Etv2 CDS flanked by Tol2 sites.

\section{Replicates:}

All experiments for the assessment of phenotype and expression patterns were replicated in at least two independent experiments. Embryos were collected from independent crosses, and experimental processing (staining or injections) were carried out on independent occasions. Exceptions to this include the analysis of the kidney hematopoietic cells by flow from Tbx6:Gal4; UAS-CRE; A2BD and the imaging of Tbx6:Gal4; UAS-CRE; Kdrl-CSY where many embryos where processed, and the corresponding $\mathrm{n}$ are reported in the associated figure legends. The analysis of qRTPCR where 3 independent experiments were performed per condition; and the single-cell sequencing experiments, where one sequencing run was performed per time-point from a pool of at least 100 embryos within the corresponding transgenic background. 


\section{Acknowledgements:}

We thank members of the Traver laboratory for helpful discussions, the UCSD Institute for Genomic Medicine sequencing core for their support on the scRNA-seq sample preparation and sequencing, and Stephanie Grainger for discussions and careful editing of the manuscript.

\section{Author Contributions:}

PS-H and CP conceived, designed and conducted experiments and analysis, and wrote the manuscript. OS conducted experiments and analysis. DT supervised experiments and edited the manuscript.

\section{Funding:}

This work was supported by the National Institute of Health [R01-DK074482 to D.T. and P.S.-H.]; National Institute of Health [T32-HL086344 to P.S.-H.]; OS was funded by American Heart Association [19POST34380328].

\section{References:}

Aird, W.C., 2007. Phenotypic heterogeneity of the endothelium: II. Representative vascular beds. Circ Res 100, 174-190.

Alunni, A., Krecsmarik, M., Bosco, A., Galant, S., Pan, L., Moens, C.B., Bally-Cuif, L., 2013. Notch3 signaling gates cell cycle entry and limits neural stem cell amplification in the adult pallium. Development 140, 3335-3347.

Ambler, C.A., Nowicki, J.L., Burke, A.C., Bautch, V.L., 2001. Assembly of trunk and limb blood vessels involves extensive migration and vasculogenesis of somite-derived angioblasts. Dev Biol 234, 352-364.

Atkins, G.B., Jain, M.K., Hamik, A., 2011. Endothelial differentiation: molecular mechanisms of specification and heterogeneity. Arterioscler Thromb Vasc Biol 31, 14761484.

Bedford, L., Walker, R., Kondo, T., van Cruchten, I., King, E.R., Sablitzky, F., 2005. Id4 is required for the correct timing of neural differentiation. Dev Biol 280, 386-395. 
Beier, J.P., Bitto, F.F., Lange, C., Klumpp, D., Arkudas, A., Bleiziffer, O., Boos, A.M., Horch, R.E., Kneser, U., 2011. Myogenic differentiation of mesenchymal stem cells cocultured with primary myoblasts. Cell Biol Int 35, 397-406.

Bingham, S., Chaudhari, S., Vanderlaan, G., Itoh, M., Chitnis, A., Chandrasekhar, A., 2003. Neurogenic phenotype of mind bomb mutants leads to severe patterning defects in the zebrafish hindbrain. Dev Dyn 228, 451-463.

Borello, U., Berarducci, B., Murphy, P., Bajard, L., Buffa, V., Piccolo, S., Buckingham, M., Cossu, G., 2006. The Wnt/beta-catenin pathway regulates Gli-mediated Myf5 expression during somitogenesis. Development 133, 3723-3732.

Burns, C.E., Traver, D., Mayhall, E., Shepard, J.L., Zon, L.I., 2005. Hematopoietic stem cell fate is established by the Notch-Runx pathway. Genes Dev 19, 2331-2342.

Bussmann, J., Schulte-Merker, S., 2011. Rapid BAC selection for tol2-mediated transgenesis in zebrafish. Development 138, 4327-4332.

Butko, E., Distel, M., Pouget, C., Weijts, B., Kobayashi, I., Ng, K., Mosimann, C., Poulain, F.E., McPherson, A., Ni, C.W., Stachura, D.L., Del Cid, N., Espin-Palazon, R., Lawson, N.D., Dorsky, R., Clements, W.K., Traver, D., 2015. Gata2b is a restricted early regulator of hemogenic endothelium in the zebrafish embryo. Development 142, 1050-1061.

Butler, J.M., Gars, E.J., James, D.J., Nolan, D.J., Scandura, J.M., Rafii, S., 2012. Development of a vascular niche platform for expansion of repopulating human cord blood stem and progenitor cells. Blood 120, 1344-1347.

Butler, J.M., Nolan, D.J., Vertes, E.L., Varnum-Finney, B., Kobayashi, H., Hooper, A.T., Seandel, M., Shido, K., White, I.A., Kobayashi, M., Witte, L., May, C., Shawber, C., Kimura, Y., Kitajewski, J., Rosenwaks, Z., Bernstein, I.D., Rafii, S., 2010. Endothelial cells are essential for the self-renewal and repopulation of Notch-dependent hematopoietic stem cells. Cell Stem Cell 6, 251-264.

Butler, J.M., Rafii, S., 2012. Generation of a vascular niche for studying stem cell homeostasis. Methods Mol Biol 904, 221-233.

Casie Chetty, S., Rost, M.S., Enriquez, J.R., Schumacher, J.A., Baltrunaite, K., Rossi, A., Stainier, D.Y., Sumanas, S., 2017. Vegf signaling promotes vascular endothelial differentiation by modulating etv2 expression. Dev Biol 424, 147-161.

Charbord, P., Pouget, C., Binder, H., Dumont, F., Stik, G., Levy, P., Allain, F., Marchal, C., Richter, J., Uzan, B., Pflumio, F., Letourneur, F., Wirth, H., Dzierzak, E., Traver, D., Jaffredo, T., Durand, C., 2014. A systems biology approach for defining the molecular framework of the hematopoietic stem cell niche. Cell Stem Cell 15, 376-391.

Childs, S., Chen, J.N., Garrity, D.M., Fishman, M.C., 2002. Patterning of angiogenesis in the zebrafish embryo. Development 129, 973-982.

Christ, B., Ordahl, C.P., 1995. Early stages of chick somite development. Anat Embryol (Berl) 191, 381-396.

Crisan, M., Kartalaei, P.S., Vink, C.S., Yamada-Inagawa, T., Bollerot, K., van, I.W., van der Linden, R., de Sousa Lopes, S.M., Monteiro, R., Mummery, C., Dzierzak, E., 2015. BMP signalling differentially regulates distinct haematopoietic stem cell types. Nat Commun 6, 8040.

Distel, M., Wullimann, M.F., Koster, R.W., 2009. Optimized Gal4 genetics for permanent gene expression mapping in zebrafish. Proc Natl Acad Sci U S A 106, 13365-13370. 
Durand, C., Robin, C., Bollerot, K., Baron, M.H., Ottersbach, K., Dzierzak, E., 2007. Embryonic stromal clones reveal developmental regulators of definitive hematopoietic stem cells. Proc Natl Acad Sci U S A 104, 20838-20843.

Eichmann, A., Marcelle, C., Breant, C., Le Douarin, N.M., 1993. Two molecules related to the VEGF receptor are expressed in early endothelial cells during avian embryonic development. Mech Dev 42, 33-48.

Ema, M., Takahashi, S., Rossant, J., 2006. Deletion of the selection cassette, but not cisacting elements, in targeted Flk1-lacZ allele reveals Flk1 expression in multipotent mesodermal progenitors. Blood 107, 111-117.

Esner, M., Meilhac, S.M., Relaix, F., Nicolas, J.F., Cossu, G., Buckingham, M.E., 2006. Smooth muscle of the dorsal aorta shares a common clonal origin with skeletal muscle of the myotome. Development 133, 737-749.

Fang, J.S., Coon, B.G., Gillis, N., Chen, Z., Qiu, J., Chittenden, T.W., Burt, J.M., Schwartz, M.A., Hirschi, K.K., 2017. Shear-induced Notch-Cx37-p27 axis arrests endothelial cell cycle to enable arterial specification. Nat Commun 8, 2149.

Garcia-Martinez, V., Schoenwolf, G.C., 1992. Positional control of mesoderm movement and fate during avian gastrulation and neurulation. Dev Dyn 193, 249-256.

Gering, M., Patient, R., 2005. Hedgehog signaling is required for adult blood stem cell formation in zebrafish embryos. Dev Cell 8, 389-400.

Gori, J.L., Butler, J.M., Chan, Y.Y., Chandrasekaran, D., Poulos, M.G., Ginsberg, M., Nolan, D.J., Elemento, O., Wood, B.L., Adair, J.E., Rafii, S., Kiem, H.P., 2015. Vascular niche promotes hematopoietic multipotent progenitor formation from pluripotent stem cells. J Clin Invest 125, 1243-1254.

Gori, J.L., Butler, J.M., Kunar, B., Poulos, M.G., Ginsberg, M., Nolan, D.J., Norgaard, Z.K., Adair, J.E., Rafii, S., Kiem, H.P., 2017. Endothelial Cells Promote Expansion of Long-Term Engrafting Marrow Hematopoietic Stem and Progenitor Cells in Primates. Stem Cells Transl Med 6, 864-876.

Guiu, J., Shimizu, R., D'Altri, T., Fraser, S.T., Hatakeyama, J., Bresnick, E.H., Kageyama, R., Dzierzak, E., Yamamoto, M., Espinosa, L., Bigas, A., 2013. Hes repressors are essential regulators of hematopoietic stem cell development downstream of Notch signaling. J Exp Med 210, 71-84.

Guo, P., Poulos, M.G., Palikuqi, B., Badwe, C.R., Lis, R., Kunar, B., Ding, B.S., Rabbany, S.Y., Shido, K., Butler, J.M., Rafii, S., 2017. Endothelial jagged-2 sustains hematopoietic stem and progenitor reconstitution after myelosuppression. J Clin Invest 127, 4242-4256. Hadland, B.K., Varnum-Finney, B., Poulos, M.G., Moon, R.T., Butler, J.M., Rafii, S., Bernstein, I.D., 2015. Endothelium and NOTCH specify and amplify aorta-gonadmesonephros-derived hematopoietic stem cells. J Clin Invest 125, 2032-2045.

Helsel, A.R., Yang, Q.E., Oatley, M.J., Lord, T., Sablitzky, F., Oatley, J.M., 2017. ID4 levels dictate the stem cell state in mouse spermatogonia. Development 144, 624-634.

Henninger, J., Santoso, B., Hans, S., Durand, E., Moore, J., Mosimann, C., Brand, M., Traver, D., Zon, L., 2017. Clonal fate mapping quantifies the number of haematopoietic stem cells that arise during development. Nat Cell Biol 19, 17-27.

Herbert, S.P., Huisken, J., Kim, T.N., Feldman, M.E., Houseman, B.T., Wang, R.A., Shokat, K.M., Stainier, D.Y., 2009. Arterial-venous segregation by selective cell sprouting: an alternative mode of blood vessel formation. Science 326, 294-298. 
Herbert, S.P., Stainier, D.Y.R., 2011. Molecular control of endothelial cell behaviour during blood vessel morphogenesis. Nature reviews. Molecular cell biology 12, 551-564. Hernandez-Hernandez, J.M., Garcia-Gonzalez, E.G., Brun, C.E., Rudnicki, M.A., 2017. The myogenic regulatory factors, determinants of muscle development, cell identity and regeneration. Semin Cell Dev Biol 72, 10-18.

Hong, C.C., Peterson, Q.P., Hong, J.Y., Peterson, R.T., 2006. Artery/vein specification is governed by opposing phosphatidylinositol-3 kinase and MAP kinase/ERK signaling. Curr Biol 16, 1366-1372.

Hubner, K., Grassme, K.S., Rao, J., Wenke, N.K., Zimmer, C.L., Korte, L., Muller, K., Sumanas, S., Greber, B., Herzog, W., 2017. Wnt signaling positively regulates endothelial cell fate specification in the Fli1a-positive progenitor population via Lef1. Dev Biol 430, 142-155.

Isogai, S., Lawson, N.D., Torrealday, S., Horiguchi, M., Weinstein, B.M., 2003. Angiogenic network formation in the developing vertebrate trunk. Development 130, 5281-5290.

Itoh, M., Kim, C.H., Palardy, G., Oda, T., Jiang, Y.J., Maust, D., Yeo, S.Y., Lorick, K., Wright, G.J., Ariza-McNaughton, L., Weissman, A.M., Lewis, J., Chandrasekharappa, S.C., Chitnis, A.B., 2003. Mind bomb is a ubiquitin ligase that is essential for efficient activation of Notch signaling by Delta. Dev Cell 4, 67-82.

Jin, H., Xu, J., Wen, Z., 2007. Migratory path of definitive hematopoietic stem/progenitor cells during zebrafish development. Blood 109, 5208-5214.

Jin, S.W., Beis, D., Mitchell, T., Chen, J.N., Stainier, D.Y., 2005. Cellular and molecular analyses of vascular tube and lumen formation in zebrafish. Development 132, 51995209.

Jones, J.M., Montcouquiol, M., Dabdoub, A., Woods, C., Kelley, M.W., 2006. Inhibitors of differentiation and DNA binding (Ids) regulate Math1 and hair cell formation during the development of the organ of Corti. J Neurosci 26, 550-558.

Ju, B., Chong, S.W., He, J., Wang, X., Xu, Y., Wan, H., Tong, Y., Yan, T., Korzh, V., Gong, Z., 2003. Recapitulation of fast skeletal muscle development in zebrafish by transgenic expression of GFP under the mylz2 promoter. Dev Dyn 227, 14-26.

Kardon, G., Campbell, J.K., Tabin, C.J., 2002. Local extrinsic signals determine muscle and endothelial cell fate and patterning in the vertebrate limb. Dev Cell 3, 533-545.

Kim, A.D., Melick, C.H., Clements, W.K., Stachura, D.L., Distel, M., Panakova, D., MacRae, C., Mork, L.A., Crump, J.G., Traver, D., 2014. Discrete Notch signaling requirements in the specification of hematopoietic stem cells. EMBO J 33, 2363-2373.

Kobayashi, H., Butler, J.M., O'Donnell, R., Kobayashi, M., Ding, B.S., Bonner, B., Chiu, V.K., Nolan, D.J., Shido, K., Benjamin, L., Rafii, S., 2010. Angiocrine factors from Aktactivated endothelial cells balance self-renewal and differentiation of haematopoietic stem cells. Nat Cell Biol 12, 1046-1056.

Kobayashi, I., Kobayashi-Sun, J., Kim, A.D., Pouget, C., Fujita, N., Suda, T., Traver, D., 2014. Jam1a-Jam2a interactions regulate haematopoietic stem cell fate through Notch signalling. Nature 512, 319-323.

Kohli, V., Schumacher, J.A., Desai, S.P., Rehn, K., Sumanas, S., 2013. Arterial and venous progenitors of the major axial vessels originate at distinct locations. Dev Cell 25, 196-206. 
La Manno, G., Soldatov, R., Zeisel, A., Braun, E., Hochgerner, H., Petukhov, V., Lidschreiber, K., Kastriti, M.E., Lonnerberg, P., Furlan, A., Fan, J., Borm, L.E., Liu, Z., van Bruggen, D., Guo, J., He, X., Barker, R., Sundstrom, E., Castelo-Branco, G., Cramer, P., Adameyko, I., Linnarsson, S., Kharchenko, P.V., 2018. RNA velocity of single cells. Nature 560, 494-498.

Lawson, N.D., Mugford, J.W., Diamond, B.A., Weinstein, B.M., 2003. phospholipase C gamma-1 is required downstream of vascular endothelial growth factor during arterial development. Genes Dev 17, 1346-1351.

Lawson, N.D., Scheer, N., Pham, V.N., Kim, C.H., Chitnis, A.B., Campos-Ortega, J.A., Weinstein, B.M., 2001. Notch signaling is required for arterial-venous differentiation during embryonic vascular development. Development 128, 3675-3683.

Lawson, N.D., Vogel, A.M., Weinstein, B.M., 2002. sonic hedgehog and vascular endothelial growth factor act upstream of the Notch pathway during arterial endothelial differentiation. Dev Cell 3, 127-136.

Lawson, N.D., Weinstein, B.M., 2002. In vivo imaging of embryonic vascular development using transgenic zebrafish. Dev Biol 248, 307-318.

Leeanansaksiri, W., Wang, H., Gooya, J.M., Renn, K., Abshari, M., Tsai, S., Keller, J.R., 2005. IL-3 induces inhibitor of DNA-binding protein-1 in hemopoietic progenitor cells and promotes myeloid cell development. J Immunol 174, 7014-7021.

Lempereur, A., Canto, P.Y., Richard, C., Martin, S., Thalgott, J., Raymond, K., Lebrin, F., Drevon, C., Jaffredo, T., 2018. The TGFbeta pathway is a key player for the endothelialto-hematopoietic transition in the embryonic aorta. Dev Biol 434, 292-303.

Light, W., Vernon, A.E., Lasorella, A., lavarone, A., LaBonne, C., 2005. Xenopus Id3 is required downstream of Myc for the formation of multipotent neural crest progenitor cells. Development 132, 1831-1841.

Lis, R., Karrasch, C.C., Poulos, M.G., Kunar, B., Redmond, D., Duran, J.G.B., Badwe, C.R., Schachterle, W., Ginsberg, M., Xiang, J., Tabrizi, A.R., Shido, K., Rosenwaks, Z., Elemento, O., Speck, N.A., Butler, J.M., Scandura, J.M., Rafii, S., 2017. Conversion of adult endothelium to immunocompetent haematopoietic stem cells. Nature 545, 439-445. Malaguti, M., Migueles, R.P., Blin, G., Lin, C.Y., Lowell, S., 2019. Id1 Stabilizes Epiblast Identity by Sensing Delays in Nodal Activation and Adjusting the Timing of Differentiation. Dev Cell 50, 462-477 e465.

Mankoo, B.S., Skuntz, S., Harrigan, I., Grigorieva, E., Candia, A., Wright, C.V., Arnheiter, H., Pachnis, V., 2003. The concerted action of Meox homeobox genes is required upstream of genetic pathways essential for the formation, patterning and differentiation of somites. Development 130, 4655-4664.

Marcelo, K.L., Goldie, L.C., Hirschi, K.K., 2013. Regulation of endothelial cell differentiation and specification. Circ Res 112, 1272-1287.

Martin, B.L., Kimelman, D., 2012. Canonical Wnt signaling dynamically controls multiple stem cell fate decisions during vertebrate body formation. Dev Cell 22, 223-232.

Mayeuf-Louchart, A., Lagha, M., Danckaert, A., Rocancourt, D., Relaix, F., Vincent, S.D., Buckingham, M., 2014. Notch regulation of myogenic versus endothelial fates of cells that migrate from the somite to the limb. Proc Natl Acad Sci U S A 111, 8844-8849.

Mayeuf-Louchart, A., Montarras, D., Bodin, C., Kume, T., Vincent, S.D., Buckingham, M., 2016. Endothelial cell specification in the somite is compromised in Pax3-positive 
progenitors of Foxc1/2 conditional mutants, with loss of forelimb myogenesis. Development 143, 872-879.

Moro, E., Ozhan-Kizil, G., Mongera, A., Beis, D., Wierzbicki, C., Young, R.M., Bournele, D., Domenichini, A., Valdivia, L.E., Lum, L., Chen, C., Amatruda, J.F., Tiso, N., Weidinger, G., Argenton, F., 2012. In vivo Wnt signaling tracing through a transgenic biosensor fish reveals novel activity domains. Dev Biol 366, 327-340.

Mosimann, C., Panakova, D., Werdich, A.A., Musso, G., Burger, A., Lawson, K.L., Carr, L.A., Nevis, K.R., Sabeh, M.K., Zhou, Y., Davidson, A.J., DiBiase, A., Burns, C.E., Burns, C.G., MacRae, C.A., Zon, L.I., 2015. Chamber identity programs drive early functional partitioning of the heart. Nat Commun 6, 8146.

Murayama, E., Kissa, K., Zapata, A., Mordelet, E., Briolat, V., Lin, H.F., Handin, R.I., Herbomel, P., 2006. Tracing hematopoietic precursor migration to successive hematopoietic organs during zebrafish development. Immunity 25, 963-975.

Nguyen, P.D., Hollway, G.E., Sonntag, C., Miles, L.B., Hall, T.E., Berger, S., Fernandez, K.J., Gurevich, D.B., Cole, N.J., Alaei, S., Ramialison, M., Sutherland, R.L., Polo, J.M., Lieschke, G.J., Currie, P.D., 2014. Haematopoietic stem cell induction by somite-derived endothelial cells controlled by meox1. Nature 512, 314-318.

Noden, D.M., 1989. Embryonic origins and assembly of blood vessels. Am Rev Respir Dis 140, 1097-1103.

Pardanaud, L., Luton, D., Prigent, M., Bourcheix, L.M., Catala, M., Dieterlen-Lievre, F., 1996. Two distinct endothelial lineages in ontogeny, one of them related to hemopoiesis. Development 122, 1363-1371.

Parsons, M.J., Pisharath, H., Yusuff, S., Moore, J.C., Siekmann, A.F., Lawson, N., Leach, S.D., 2009. Notch-responsive cells initiate the secondary transition in larval zebrafish pancreas. Mech Dev 126, 898-912.

Plein, A., Fantin, A., Denti, L., Pollard, J.W., Ruhrberg, C., 2018. Erythro-myeloid progenitors contribute endothelial cells to blood vessels. Nature 562, 223-228.

Potente, M., Makinen, T., 2017. Vascular heterogeneity and specialization in development and disease. Nat Rev Mol Cell Biol 18, 477-494.

Pouget, C., Gautier, R., Teillet, M.A., Jaffredo, T., 2006. Somite-derived cells replace ventral aortic hemangioblasts and provide aortic smooth muscle cells of the trunk. Development 133, 1013-1022.

Pouget, C., Peterkin, T., Simoes, F.C., Lee, Y., Traver, D., Patient, R., 2014. FGF signalling restricts haematopoietic stem cell specification via modulation of the BMP pathway. Nat Commun 5, 5588.

Pouget, C., Pottin, K., Jaffredo, T., 2008. Sclerotomal origin of vascular smooth muscle cells and pericytes in the embryo. Dev Biol 315, 437-447.

Psychoyos, D., Stern, C.D., 1996. Fates and migratory routes of primitive streak cells in the chick embryo. Development 122, 1523-1534.

Raynaud, C.M., Butler, J.M., Halabi, N.M., Ahmad, F.S., Ahmed, B., Rafii, S., Rafii, A., 2013. Endothelial cells provide a niche for placental hematopoietic stem/progenitor cell expansion through broad transcriptomic modification. Stem Cell Res 11, 1074-1090.

Reischauer, S., Stone, O.A., Villasenor, A., Chi, N., Jin, S.W., Martin, M., Lee, M.T., Fukuda, N., Marass, M., Witty, A., Fiddes, I., Kuo, T., Chung, W.S., Salek, S., Lerrigo, R., Alsio, J., Luo, S., Tworus, D., Augustine, S.M., Mucenieks, S., Nystedt, B., Giraldez, A.J., 
Schroth, G.P., Andersson, O., Stainier, D.Y., 2016. Cloche is a bHLH-PAS transcription factor that drives haemato-vascular specification. Nature 535, 294-298.

Relaix, F., Rocancourt, D., Mansouri, A., Buckingham, M., 2005. A Pax3/Pax7-dependent population of skeletal muscle progenitor cells. Nature 435, 948-953.

Risau, W., Flamme, I., 1995. Vasculogenesis. Annu Rev Cell Dev Biol 11, 73-91.

Salucci, S., Baldassarri, V., Falcieri, E., Burattini, S., 2015. alpha-Actinin involvement in Z-disk assembly during skeletal muscle $\mathrm{C} 2 \mathrm{C} 12$ cells in vitro differentiation. Micron 68, 4753.

Sandler, V.M., Lis, R., Liu, Y., Kedem, A., James, D., Elemento, O., Butler, J.M., Scandura, J.M., Rafii, S., 2014. Reprogramming human endothelial cells to haematopoietic cells requires vascular induction. Nature 511, 312-318.

Scheer, N., Groth, A., Hans, S., Campos-Ortega, J.A., 2001. An instructive function for Notch in promoting gliogenesis in the zebrafish retina. Development 128, 1099-1107.

Schienda, J., Engleka, K.A., Jun, S., Hansen, M.S., Epstein, J.A., Tabin, C.J., Kunkel, L.M., Kardon, G., 2006. Somitic origin of limb muscle satellite and side population cells. Proc Natl Acad Sci U S A 103, 945-950.

Schoenwolf, G.C., Garcia-Martinez, V., Dias, M.S., 1992. Mesoderm movement and fate during avian gastrulation and neurulation. Dev Dyn 193, 235-248.

Schuster-Gossler, K., Cordes, R., Gossler, A., 2007. Premature myogenic differentiation and depletion of progenitor cells cause severe muscle hypotrophy in Delta1 mutants. Proc Natl Acad Sci U S A 104, 537-542.

Selleck, M.A., Stern, C.D., 1991. Fate mapping and cell lineage analysis of Hensen's node in the chick embryo. Development 112, 615-626.

Siekmann, A.F., Lawson, N.D., 2007. Notch signalling and the regulation of angiogenesis. Cell Adh Migr 1, 104-106.

Sjoblom, B., Salmazo, A., Djinovic-Carugo, K., 2008. Alpha-actinin structure and regulation. Cell Mol Life Sci 65, 2688-2701.

Stainier, D.Y., Weinstein, B.M., Detrich, H.W., 3rd, Zon, L.I., Fishman, M.C., 1995. Cloche, an early acting zebrafish gene, is required by both the endothelial and hematopoietic lineages. Development 121, 3141-3150.

Stuart, T., Butler, A., Hoffman, P., Hafemeister, C., Papalexi, E., Mauck, W.M., 3rd, Hao, Y., Stoeckius, M., Smibert, P., Satija, R., 2019. Comprehensive Integration of Single-Cell Data. Cell 177, 1888-1902 e1821.

Tozer, S., Bonnin, M.A., Relaix, F., Di Savino, S., Garcia-Villalba, P., Coumailleau, P., Duprez, D., 2007. Involvement of vessels and PDGFB in muscle splitting during chick limb development. Development 134, 2579-2591.

Veldman, M.B., Lin, S., 2012. Etsrp/Etv2 is directly regulated by Foxc1a/b in the zebrafish angioblast. Circ Res 110, 220-229.

Veldman, M.B., Zhao, C., Gomez, G.A., Lindgren, A.G., Huang, H., Yang, H., Yao, S., Martin, B.L., Kimelman, D., Lin, S., 2013. Transdifferentiation of fast skeletal muscle into functional endothelium in vivo by transcription factor Etv2. PLoS Biol 11, e1001590.

Villefranc, J.A., Amigo, J., Lawson, N.D., 2007. Gateway compatible vectors for analysis of gene function in the zebrafish. Dev Dyn 236, 3077-3087.

Vokes, S.A., McMahon, A.P., 2004. Hedgehog signaling: iguana debuts as a nuclear gatekeeper. Curr Biol 14, R668-670. 
von Maltzahn, J., Chang, N.C., Bentzinger, C.F., Rudnicki, M.A., 2012. Wnt signaling in myogenesis. Trends Cell Biol 22, 602-609.

Wang, X., Moon, J., Dodge, M.E., Pan, X., Zhang, L., Hanson, J.M., Tuladhar, R., Ma, Z., Shi, H., Williams, N.S., Amatruda, J.F., Carroll, T.J., Lum, L., Chen, C., 2013. The development of highly potent inhibitors for porcupine. J Med Chem 56, 2700-2704.

Wilkinson, R.N., Koudijs, M.J., Patient, R.K., Ingham, P.W., Schulte-Merker, S., van Eeden, F.J., 2012. Hedgehog signaling via a calcitonin receptor-like receptor can induce arterial differentiation independently of VEGF signaling in zebrafish. Blood 120, 477-488. Wilkinson, R.N., Pouget, C., Gering, M., Russell, A.J., Davies, S.G., Kimelman, D., Patient, R., 2009. Hedgehog and Bmp polarize hematopoietic stem cell emergence in the zebrafish dorsal aorta. Dev Cell 16, 909-916.

Williams, C., Kim, S.H., Ni, T.T., Mitchell, L., Ro, H., Penn, J.S., Baldwin, S.H., SolnicaKrezel, L., Zhong, T.P., 2010. Hedgehog signaling induces arterial endothelial cell formation by repressing venous cell fate. Dev Biol 341, 196-204.

Wilting, J., Brand-Saberi, B., Huang, R., Zhi, Q., Kontges, G., Ordahl, C.P., Christ, B., 1995. Angiogenic potential of the avian somite. Dev Dyn 202, 165-171.

Wythe, J.D., Dang, L.T., Devine, W.P., Boudreau, E., Artap, S.T., He, D., Schachterle, W., Stainier, D.Y., Oettgen, P., Black, B.L., Bruneau, B.G., Fish, J.E., 2013. ETS factors regulate Vegf-dependent arterial specification. Dev Cell 26, 45-58.

Yabe, T., Hoshijima, K., Yamamoto, T., Takada, S., 2016. Quadruple zebrafish mutant reveals different roles of Mesp genes in somite segmentation between mouse and zebrafish. Development 143, 2842-2852.

Yun, K., Mantani, A., Garel, S., Rubenstein, J., Israel, M.A., 2004. Id4 regulates neural progenitor proliferation and differentiation in vivo. Development 131, 5441-5448.

Yvernogeau, L., Auda-Boucher, G., Fontaine-Perus, J., 2012. Limb bud colonization by somite-derived angioblasts is a crucial step for myoblast emigration. Development 139, 277-287.

Zhang, N., Yantiss, R.K., Nam, H.S., Chin, Y., Zhou, X.K., Scherl, E.J., Bosworth, B.P., Subbaramaiah, K., Dannenberg, A.J., Benezra, R., 2014. ID1 is a functional marker for intestinal stem and progenitor cells required for normal response to injury. Stem Cell Reports 3, 716-724.

Zhang, X.Y., Rodaway, A.R., 2007. SCL-GFP transgenic zebrafish: in vivo imaging of blood and endothelial development and identification of the initial site of definitive hematopoiesis. Dev Biol 307, 179-194.

Zhong, T.P., Childs, S., Leu, J.P., Fishman, M.C., 2001. Gridlock signalling pathway fashions the first embryonic artery. Nature 414, 216-220.

Zhou, Y., Cashman, T.J., Nevis, K.R., Obregon, P., Carney, S.A., Liu, Y., Gu, A., Mosimann, C., Sondalle, S., Peterson, R.E., Heideman, W., Burns, C.E., Burns, C.G., 2011. Latent TGF-beta binding protein 3 identifies a second heart field in zebrafish. Nature 474, 645-648.

Zywitza, V., Misios, A., Bunatyan, L., Willnow, T.E., Rajewsky, N., 2018. Single-Cell Transcriptomics Characterizes Cell Types in the Subventricular Zone and Uncovers Molecular Defects Impairing Adult Neurogenesis. Cell Rep 25, 2457-2469 e2458. 
Figure 1: Endothelial cells emerge from the dermomyotome at 12ss. A-E. Time-lapse imaging from a dorsal view of Tg(Etv2:GFP) embryos injected with mOrange:CAAX mRNA and imaged between 10ss to 15ss. A. The expression of Etv2:GFP+ cells is visible along the LPM region. At this stage, no Etv2:GFP+ cells are visible in the somites. $\mathbf{B}$. Starting at 12ss, the first Etv2:GFP ${ }^{+}$cells are detected in the lateral lip of the dermomyotome (arrowheads). Simultaneously, the LPM Etv2:GFP ${ }^{+}$cells start migrating to the midline. C. Soon after emergence, somite derived Etv2:GFP ${ }^{+}$cells change shape and become rounder (arrowheads). D-E. Etv2:GFP ${ }^{+}$cells bud off from the somite as individual cells (arrowhead). F. Dorsal view of a 12ss embryo submitted to a double fluorescent in situ hybridization for muscle progenitor maker, Pax3a (green), and endothelial marker, Etv2 (red). Pax3a expression reveals the dermomyotome compartment that contains the muscle progenitor cells. An Etv2+ cell (red) is found in the dermomyotome, co-expressing Pax3a (green and arrowhead), showing co-localization of an endothelial and muscle progenitor cell marker. G. Somitic Etv2+ cells (green) do not co-express the muscle differentiation marker myoD (red), suggesting that Etv2+ expression is restricted to the muscle progenitor region of the somite. Dashed white lines delimitate somite from the LPM (arrow).

Figure 2: Notch is required for the maintenance of a bipotent skeletal muscle progenitor population in the somite. A-F. Dorsal view of 12 ss control (A-C) and meox 1 morpholino (D-F) injected embryos. Embryos were submitted to double fluorescent in situ hybridization for Meox1 (green) and Etv2 (red). In control and morphant embryos, Meox1, Etv2 double positive cells are detected within the somite compartment (arrowhead). C, F. Overlay of Meox1 (green), Etv2 (red), and DAPI (blue). D-F. Knockdown of meox1 results in ectopic formation of double positive cells within the somite (arrowhead). G, H, Timelapse imaging of a 22hpf (26ss) Tg(phldb1:Gal4:UAS-RFP; Etv2:GFP) embryos, injected with meox1 morpholino and mOrange2:CAAX mRNA, to delineate cell boundaries. Knockdown of meox1 results in an extension of the time-period that the dermomyotome can generate Etv2:GFP ${ }^{+}$cells (arrowheads). I-K, Cross section of 12 ss Tg(Etv2:GFP) control embryos. In absence of meox1 (J), ectopic Etv2:GFP ${ }^{+}$cells are visible in epithelialized layer of the somites, compared to controls (I). In embryos coinjected with mib and meox1 morpholinos, the number of Etv2:GFP ${ }^{+}$cells within the somite 
compartment (outlined compartment), is substantially increased $(\mathbf{K})$, suggesting that Notch signaling is dispensable for SDECs specification. L-N, Lateral view of 12ss embryos analyzed by FISH for meox1 (green), etv2(red), and DAPI (blue). In Notch3 heterozygotes control (L) and mutant embryos (M), SDEC etv2 ${ }^{+}$cells are detected in the somites. N. Notch3 mutant embryos co-injected with meox1 morpholino, results in ectopic formation of Etv2 Meox1 double positive cells (arrowhead). O. qRT-PCR in 24hpf Notch3 mutant embryos and sibling controls. Genetic ablation of Notch3 results in decreased expression of muscle progenitor marker pax3a and pax $7 b$; increased expression of muscle differentiation gene, myod and myog and endothelial markers, etv2 and fli1. All

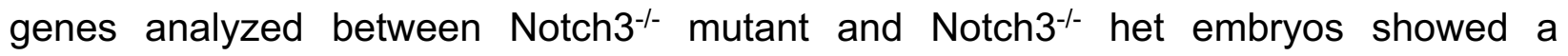
statistically significant difference $(p<0.001$, Student's t test; $n=3$.) $\mathbf{P}, \mathbf{Q}$, Notch3 mutant embryos show premature expression of MyoHIl in 48hpf embryos (Q) compared to sibling controls (P). R. Summary cartoon for the role of Notch Signaling in the maintenance of bipotent-muscle progenitors (bipotent muscle progenitors in purple and green; muscle cells in green; endothelial cells in purple).

Figure 3: NPAS4I is required for the specification of the SDECs. A-D. WISH for etv2 in 12ss embryos. B. cloche mutant embryos shows absence of etv2 expression along the A-P axis of the embryo, compared to sibling control (A). D. Similarly, cloche mutant embryos injected with Meox1 morpholino, results in loss of etv2 expression, compared to sibling control (C). E-H. Similarly, Tg(Etv2:GFP ${ }^{+/+}$(homozygous); cloche ${ }^{-/+}$) adult fish were incrossed and embryos were injected with both meox1 and mib morpholino. G, H. Cloche mutant embryos show loss of etv2:GFP expression in the LPM and somites at 12ss compared with control embryos (E, F arrowheads). I-N. Tg(cloche ${ }^{-/+}$) adult fish were incrossed and embryos co-injected with mib and meox1 morpholino, and performed a FISH for meox1 (green) and etv2 (red) at 12ss. L-N. cloche mutants shows loss of all etv2, meox1 double positive cells. O. qRT-PCR of cloche mutant embryos shows the expected loss of endothelial genes and concomitant increase of muscle differentiation genes. All genes analyzed between Cloche $^{-/-}$mutant and Cloche $^{-/-}$het embryos showed a statistically significant difference $(p<0.001$, Student's t test; $n=3$.) $\mathbf{P}, \mathbf{Q}$. Summary model by how NPAS4I might affect endothelial cell competence in PM progenitors (early 
mesoderm progenitor in grey; bipotent muscle progenitor in purple and green; muscle cells in green; endothelial cells in purple).

Figure 4: Wnt signaling is required for the regionalization of SDECs. A. FISH for meox1 (red) and antibody staining for a destabilized Wnt/TCF reporter line (green), shows somitic cells co-expression of GFP and Meox1 within the somite compartment. B. Inhibition of Wnt signaling using the chemical inhibitor IWP2 from 2ss to 15ss stage, results in decrease expression by qRT-PCR of axin2, meox1 with a concomitant increase of the expression of etv2. All genes analyzed between Wnt inhibitor and control embryos showed a statistically significant difference $(p<0.001$, Student's t test; $n=3$.) C, D. Cross section of $\operatorname{Tg}($ Etv2:GFP) embryos treated with IWP2 from 2ss -15ss stage, results in ectopic formation of Etv2:GFP ${ }^{+}$cells within the somite, D (arrowhead). E, F. IWP2 treated embryos from 2ss-12ss stage results in decrease expression of Meox1 by WISH, compared to control embryos.

Figure 5: SDECs contribute to the dorsal aorta and do not generate HSPCs. A-C. Lineage tracing of somite derived cells using $\operatorname{Tg}$ (Tbx6:Gal4; UAS:CRE; beta-actin:A2BD) shows dsRed+ cells in the vasculature region at 48hpf (arrowheads). E-J. Using a vasculature specific switched line $T g(K d r l: C S Y)$, we observe the contribution of SDECs or PLM-derived endothelial cells to the vasculature. E-G. For SDECs labelling, a PMspecific driver Tg(Tbx6:Gal4;UAS:CRE) was used. PM-derived $\mathrm{YFP}^{+}$cells are observed in the vasculature of imaged embryos. H-J. For LPM-specific labeling, a Tg(Draculin:CreERT2) was used and treated with 10um of tamoxifen starting at 8 hpf. YFP $^{+}$cells are observed in all region of the vasculature. K. Quantification of YFP ${ }^{+}$ endothelial cells from Tbx6 or Draculin switched embryos. These quantifications where based from independent experiments per transgenic background with $n=23$ for Tbx6 switched embryos and $n=9$ for Draculin switch embryos. L. Analysis of the adult kidney marrow of $\operatorname{Tg}(T b x 6: G a l 4 ;$ UAS:CRE; beta-actin:A2BD) shows no contribution to definitive blood cells (DsRed) through flow cytometry analysis whereas the FSC/SSC distribution of the unswitched BFP ${ }^{+}$cells correspond to all blood lineages (quantifications based from independent experiments with a total of $n=21$ samples). 
Figure 6: Cell clustering and cell-type-specific endothelial cell markers. A. Uniform Manifold Approximation Projection (UMAP) plots of 22hpf scRNA-seq data, 2,996 total cells that represent the endothelial lineage. Clusters were named according to their gene expression: somite derived endothelial cells (SDECs), Brain Vascular Endothelium (BVECs), Kidney Vascular Endothelial cells (KVECs), General Endothelium, Pre-HSCs Hemogenic Endothelium (HE), and Endocardium. Color-coded marker gene expression levels are shown on corresponding clusters. B. An expression heatmap of $22 \mathrm{hpf}$ single cell transcriptome showing the top predicted differentially expressed marker genes across the different clusters.

Figure 7: SDECs act as a vascular niche population for the hemogenic endothelium. A. Heatmap of genes that are differentially regulated between endothelial cells of the PLM and SDECs. B, C. Zebrafish embryos were injected with a transgene containing a somite specific promoter, Myzl2, and driving an Etv2 transgene, to ectopically induced SDECs. By WISH we observe an increase of runx1 expression of 24hpf injected embryos, compared to embryos injected with an empty Myzl2 vector. D-E Similarly, Meox1 morphant embryos exhibit an increase expression of runx1 by WISH, compared to uninjected control embryos. F-I. Conversely, overexpression of Meox1 by mRNA results in a strong reduction of the hemogenic markers runx1 and gata2b. J-K, Knockdown of meox1 results in increase expression of bmp4 in the dorsal aorta region by WISH.

Figure 8: Early Notch signaling regulates the rate of differentiation of endothelial cells.

A. Heatmap of the 20 most upregulated and downregulated genes between 1,392 $\mathrm{mib}^{-/-}$ ; and 2,817 control endothelial cells. B-E. Adapted from Zywitza et al., B. Spliced and unspliced counts are estimated by separated counting reads that incorporate intronic sequences. C-E. Model of transcriptional dynamics capturing transcription (alpha), splicing (beta), and degradation (gamma), rates involved in production of unspliced (u) and spliced (s) mRNA products and solution to the models. F, G. Velocities are visualized on a UMAP plot between Notch mutant (G) and control endothelial cells (F), using Gaussian smoothing. H. Expression pattern of unspliced-spliced phase portraits, and 
residuals are shown for arterial genes, dll4, hey2 and ephrb2a between mib mutants (right panel) and control endothelial cell types (left panel).

Figure 9: Notch Signaling and ID1 act in tandem for the proper specification of the hemogenic endothelium. A, B. mib mutants show a loss of ID1 expression in the neural tube and vasculature region compared to control sibling embryos at 24hpf. C, D Conversely, overexpression of Notch signaling in the vasculature region using Tg(Cdh5:Gal4; UAS:NICD) results in increased expression of ID1 compared to control sibling embryos. E-L Knockdown of ID1 results in normal expression of vascular genes but a substantial reduction of hemogenic marker runx1. M-P Vascular overexpression of Notch signaling with $T g(k d r l: G a l 4 ; U A S: N I C D)$ is not able to rescue runx1 expression exhibited by embryos injected with ID1 morpholino. Q-T Conversely, combined overexpression of ID1 and knockdown of Notch signaling is unable to rescue loss of runx1.

\section{Supplementary Figure 1: Bipotent muscle progenitor cells contain endothelial} potential that can span deep into the dermomyotome compartment. $A$. Max projection of $12 \mathrm{hpf}$ Notch3 mutant embryos injected with meox1 morpholino shows the extent of endothelial potential within the somite compartment (double positive meox1 (green) and etv2 (red) cells). B. Z-sections of a dermomyotome compartment, that shows the extent of double positive cells.

\section{Supplementary Figure 2: Paraxial mesoderm derived endothelial cells contribute} to the dorsal aorta in zebrafish. A, B. Cross section and $3 \mathrm{D}$ reconstruction shows contribution of $\mathrm{Tg}\left(\mathrm{Tb} \times 6: \mathrm{Gal4}\right.$;UAS:CRE, Kdrl:CSY) SDEC $\mathrm{YFP}^{+}$cells to the anterior vasculature region of the dorsal aorta. A-A"' Shows different z-sections of the image. B, B' shows 3D reconstruction.

Supplementary Figure 3: The paraxial mesoderm does not generate HSPCs. Tg(Tbx6:Gal4; UAS:CRE; beta-actin:A2BD) and Tg(Kdrl:CRE; beta-actin:A2BD) adult kidney marrows were analyzed by flow cytometry. Top row illustrates that the hematopoietic lineages of $T g(K d r l: C R E ; ~ b e t a-a c t i n: A 2 B D)$ originate from switched DsRed $^{+}$cells whereas in the Tg(Tbx6:Gal4; UAS:CRE; beta-actin:A2BD) BFP ${ }^{+}$nonswitched cells are the source of the hematopoietic system. 
Supplementary Figure 4: $\mathrm{mib}^{-/-}$single cell analysis in hemogenic endothelial cluster shows that loss of Notch signaling results in reduced expression of genes important for hematopoietic cell formation. A. Heatmap of genes specific for the PreHSPCs and hemogenic cluster showing the 20 most upregulated and downregulated genes in wild type Etv2:GFP ${ }^{+}$and mib $^{-/}$Etv2:GFP ${ }^{+}$cells isolated at $22 \mathrm{hpf}$. B. Scatter plot of differentially expressed genes between mib-/-mutant (y-axis) and control cells (x-axis). Green dots are genes upregulated in Notch mutants. Red dots are genes which expression is decreased in Notch mutants. Genes important for hematopoiesis are represented in orange.

Supplementary Figure 5: Single cell analysis in $\mathrm{mib}^{-/-}$in SDEC cluster shows that loss of Notch signaling does not affect the specification of SDECs. A. Heatmap of genes expressed in SDECs. Genetic ablation of Notch signaling has little impact on SDECs genes. B. Scatter plot of differentially expressed genes between mib mutant (yaxis) and control cells (x-axis). Green dots are genes upregulated in Notch mutants. Red dots are genes which expression is decreased in Notch mutants. Genes highly expressed in SDECs are represented in orange.

Supplementary Figure 6: ID1 morpholino validation. Knockdown of Id1 splice morpholino reduced runx1 expression. Conversely, increased dose of Id1 achieved by mRNA injection, upregulated runx1 expression in the dorsal aorta. Combined morpholino knockdown and enforced expression of Id1 restores runx1 expression to a level similar to what is observed in control sibling embryos.

Supplementary MovieS1: Time-lapse imaging of Tg(Etv2:GFP, Ph1db1:Gal4UAS:mCherry) embryos imaged between 12-16ss. Lateral view of a transgenic embryo. LPM cells are on the right and migrate under the somites. SDECs arise from the third and the fourth somites while most of the LPM cells have already ingress underneath the somites.

Supplementary MovieS2: Time-lapse imaging of IWP-L6 treated embryos in the background Tg(Etv2:GFP) injected with mOrange2:CAAX mRNA and imaged dorsally between 10-14ss. Embryos treated with the Wnt inhibitor IWP-L6 between 2ss14ss observe the ectopic formation of Etv2:GFP+ cells in the central part of the somite 


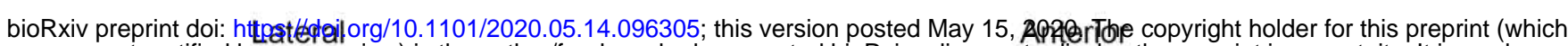
was not certified by peer review) is the author/funder, who has granted bioRxiv a license to display the preprint in perpetuity. It is made

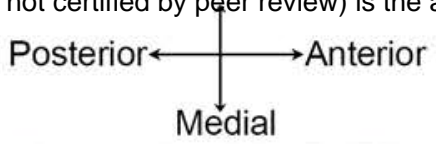
available under aCC-BY 4.0 International license.
Médial
Posterior

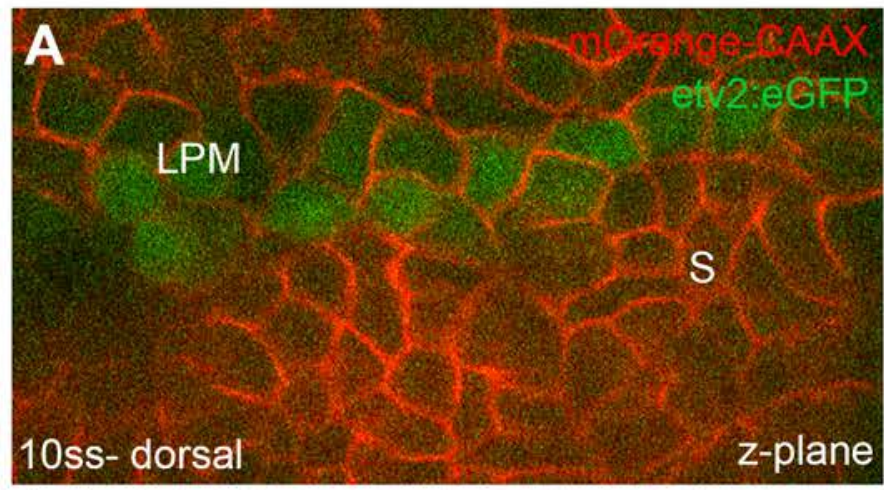

B

\section{2 ss}

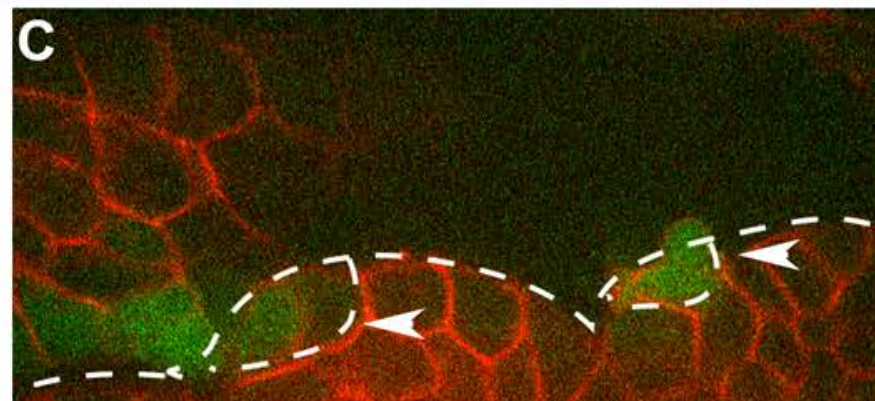

D

15ss

E

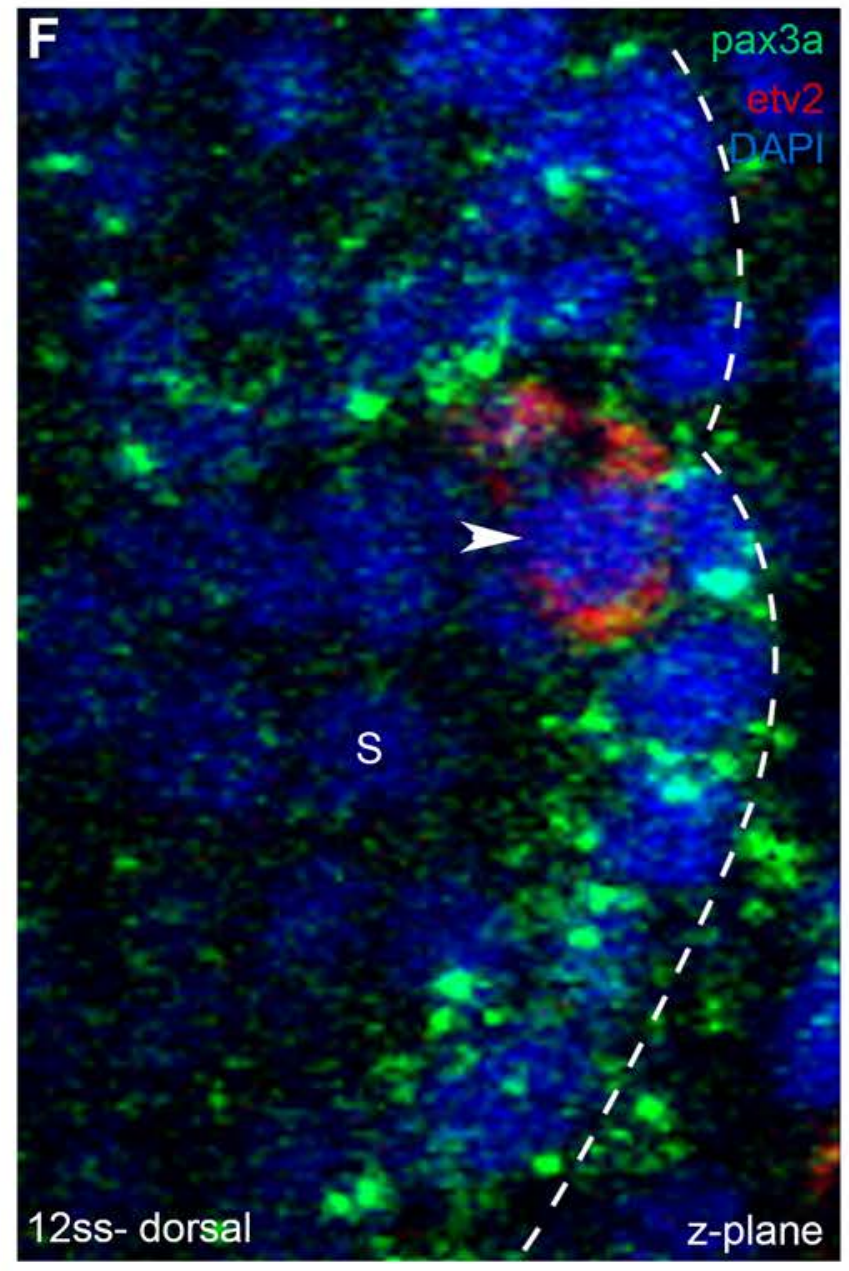

G

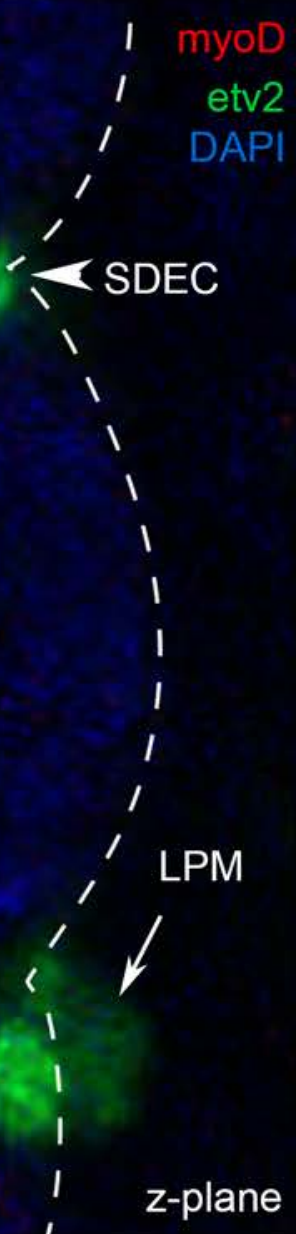


bioRxiv preprint doi: https://doi.org/10.1101/2020.05.14.096305; this version posted May 15, 2020. The copyright holder for this preprint (which

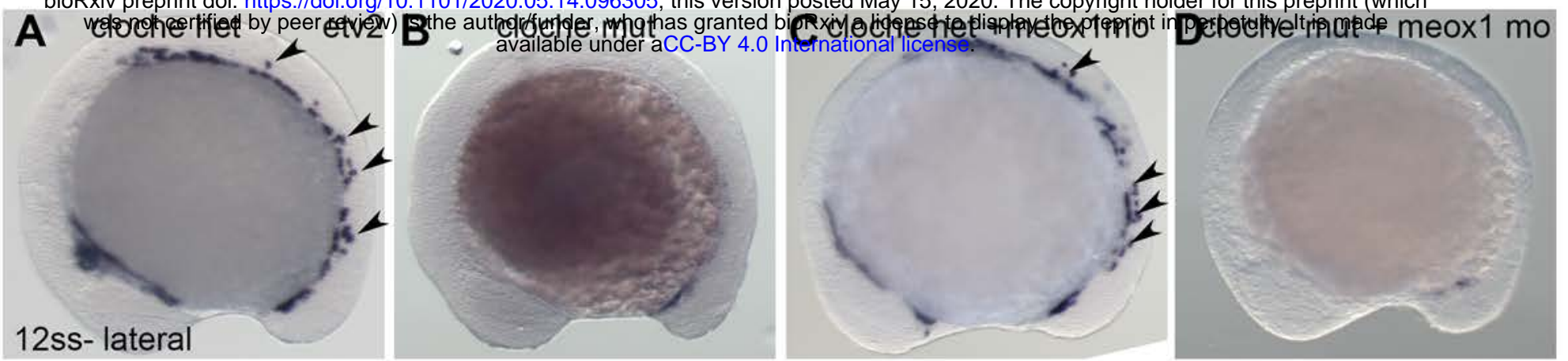

clo het, mib mut,meox1 mo; etv2:eGFP homo

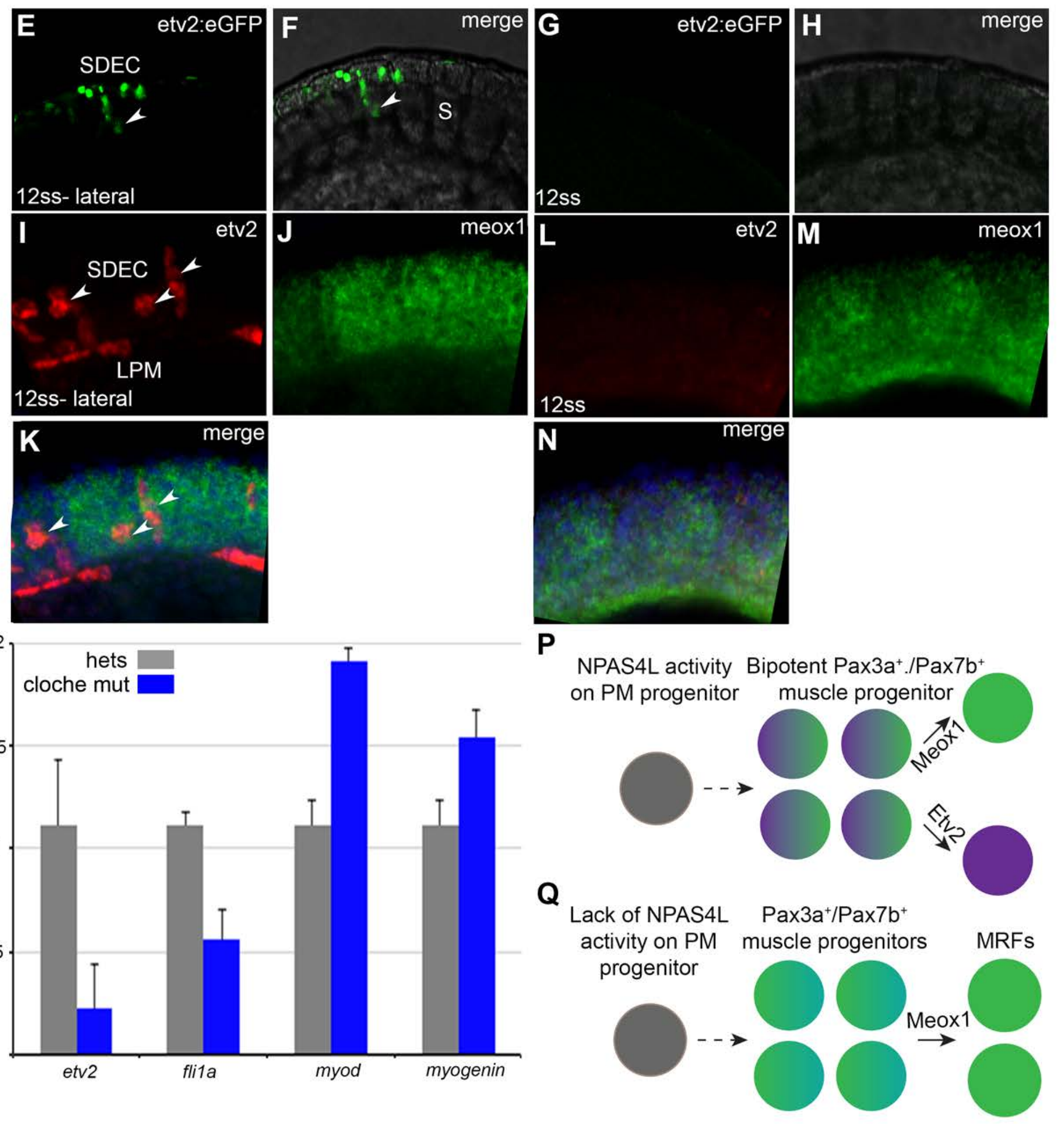


bioRxiv preprint doi: https://doi.org/10.1101/2020.05.14.096305; this version posted May 15, 2020. The copyright holder for this preprint (which

was not certified by peer review) is the author/funder, who has granted bioRxiv a license to display the preprint in perpetuity. It is made available under aCC-BY 4.0 International license.
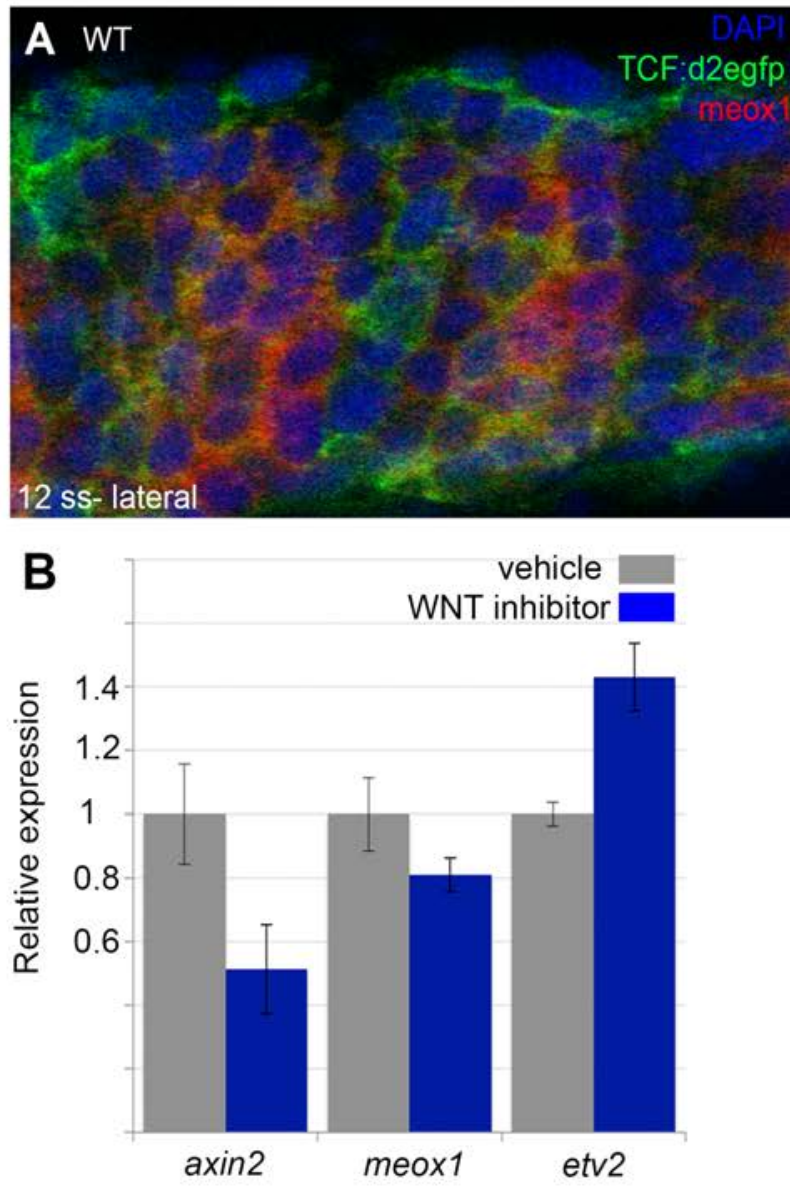
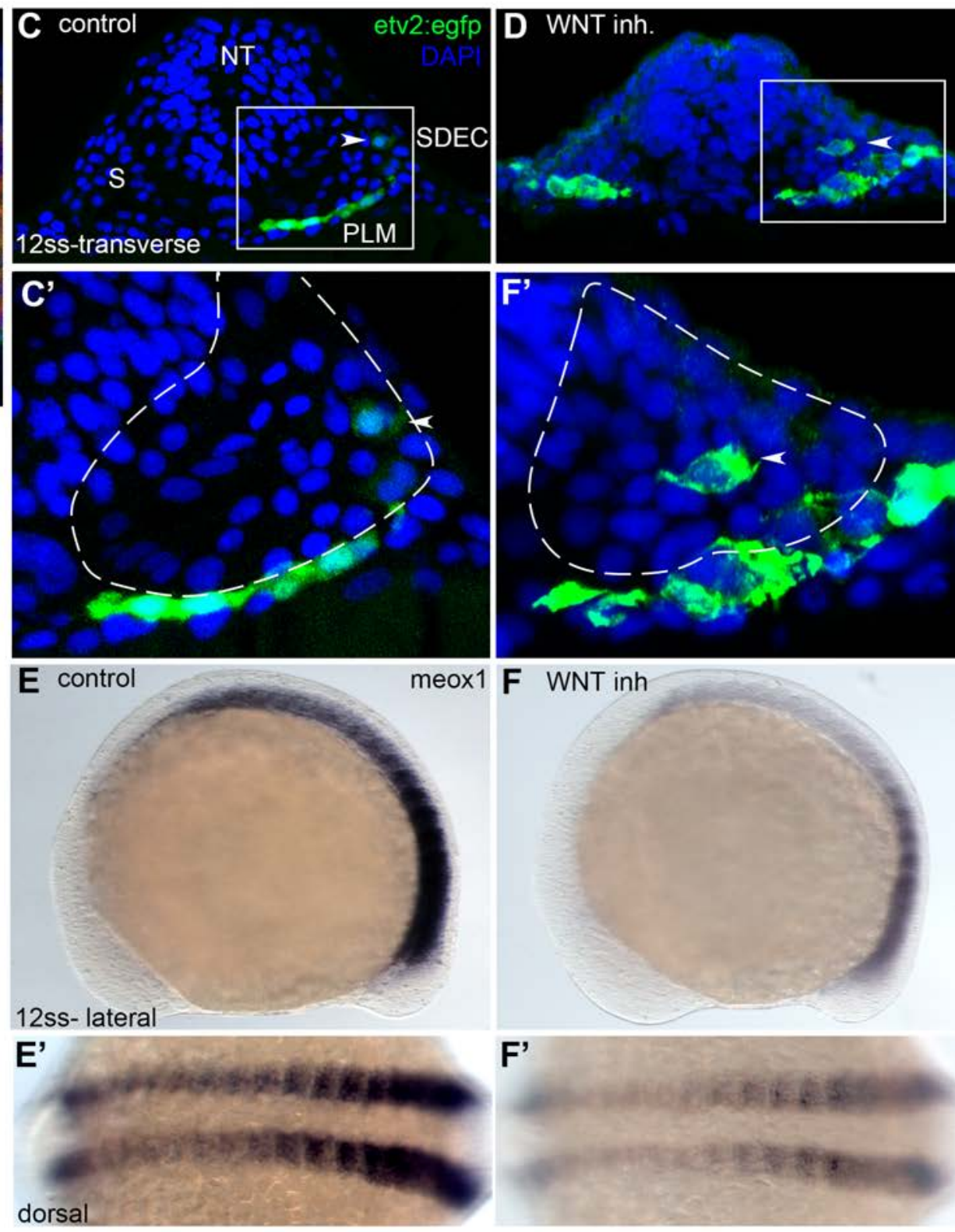
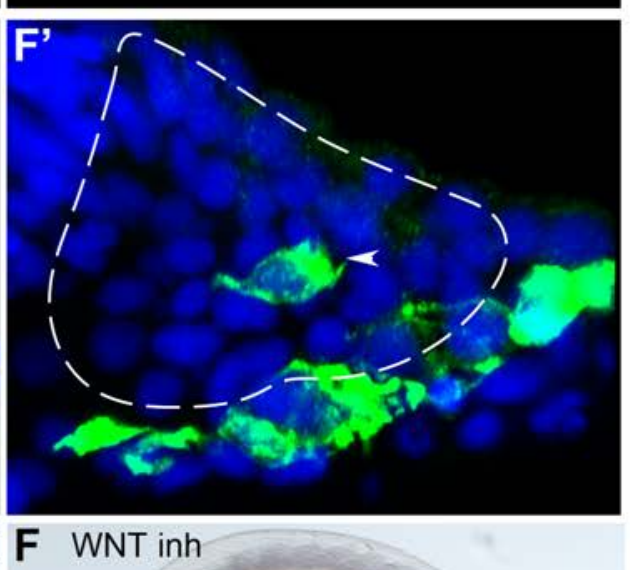

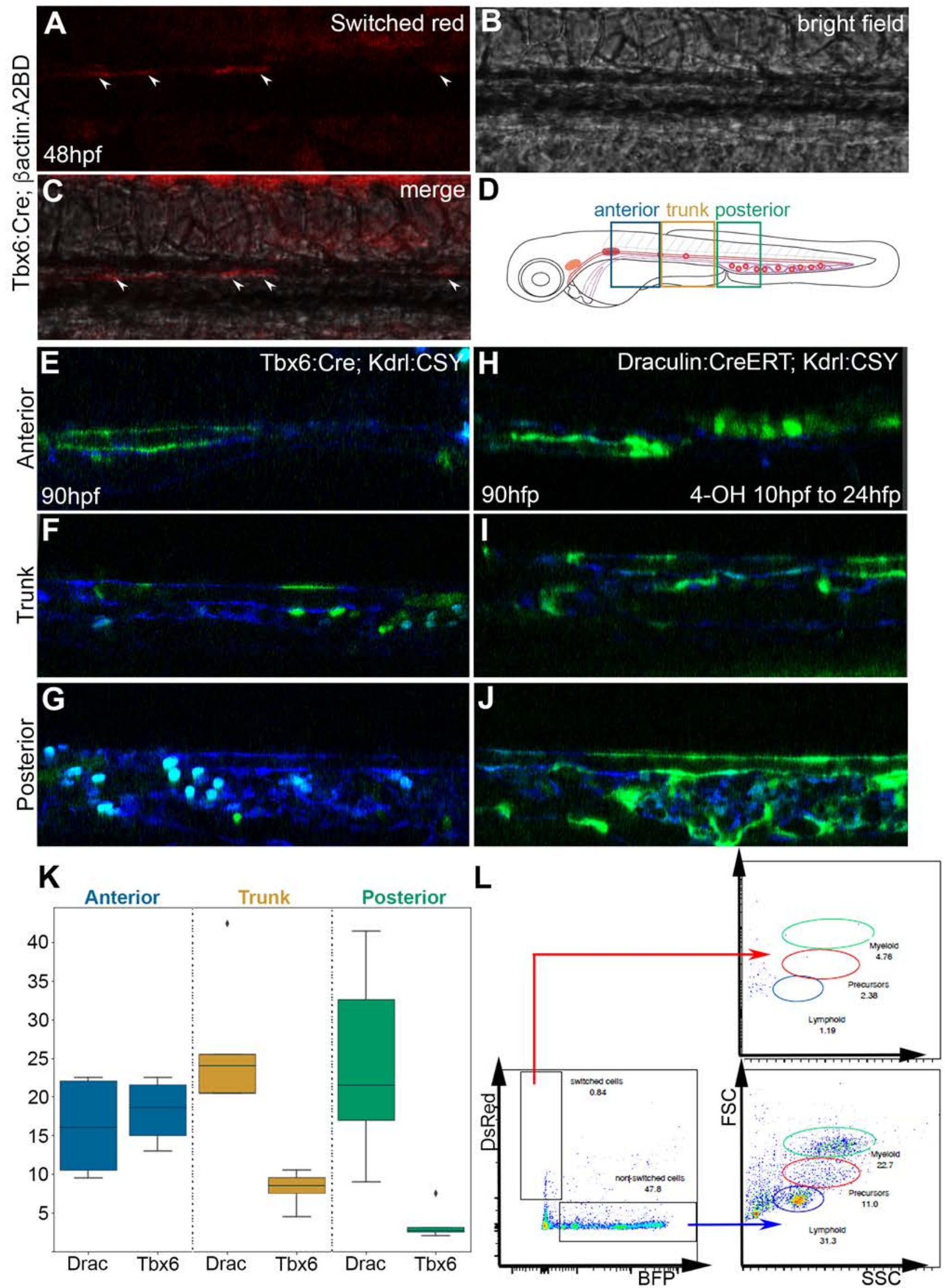
A

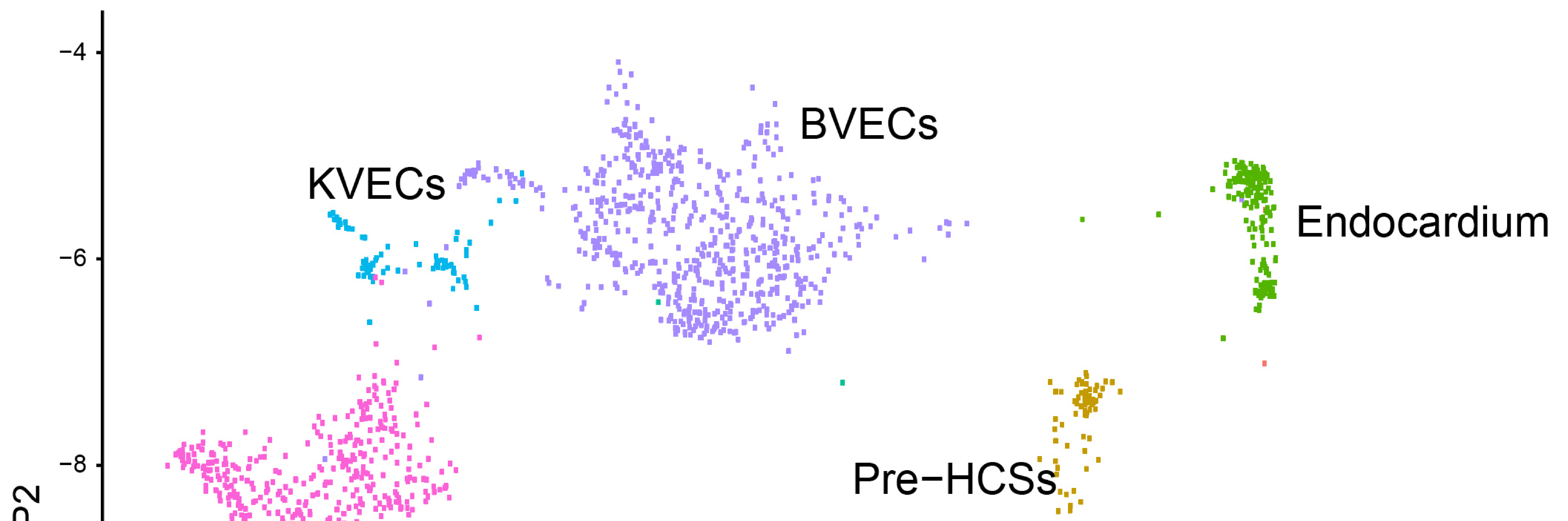

B

\section{SDECS}
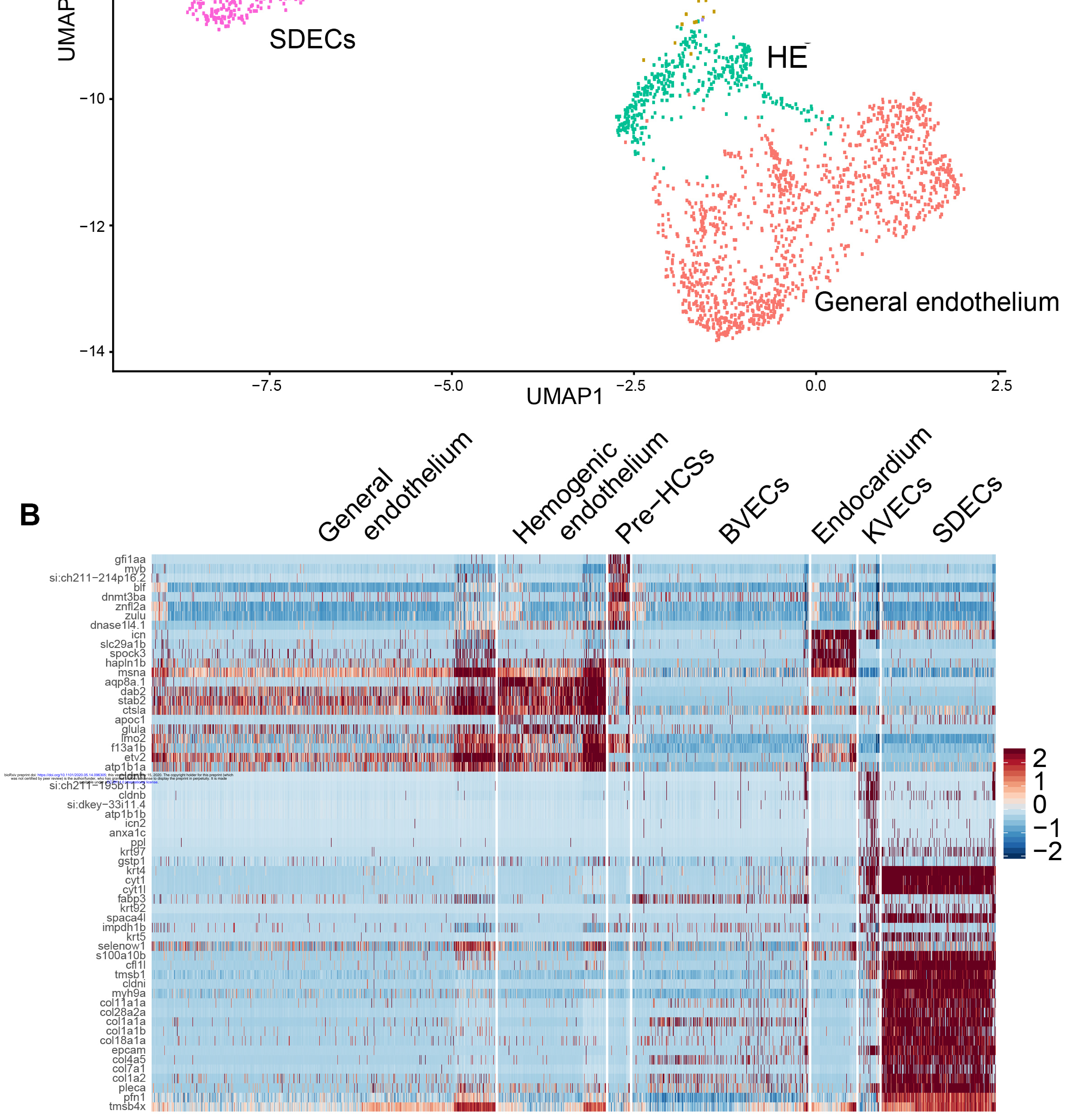
bioRxiv preprint doi: https://doi.org/10.1101/2020.05.14.096305; this version posted May 15,2020 . The copyright holder for this preprint (which was not certified by peer review) is the author/funder, who has granted bioRxiv a license to display the preprint in perpetuity. It is made

A available under aCC-BY 4.0 International license.

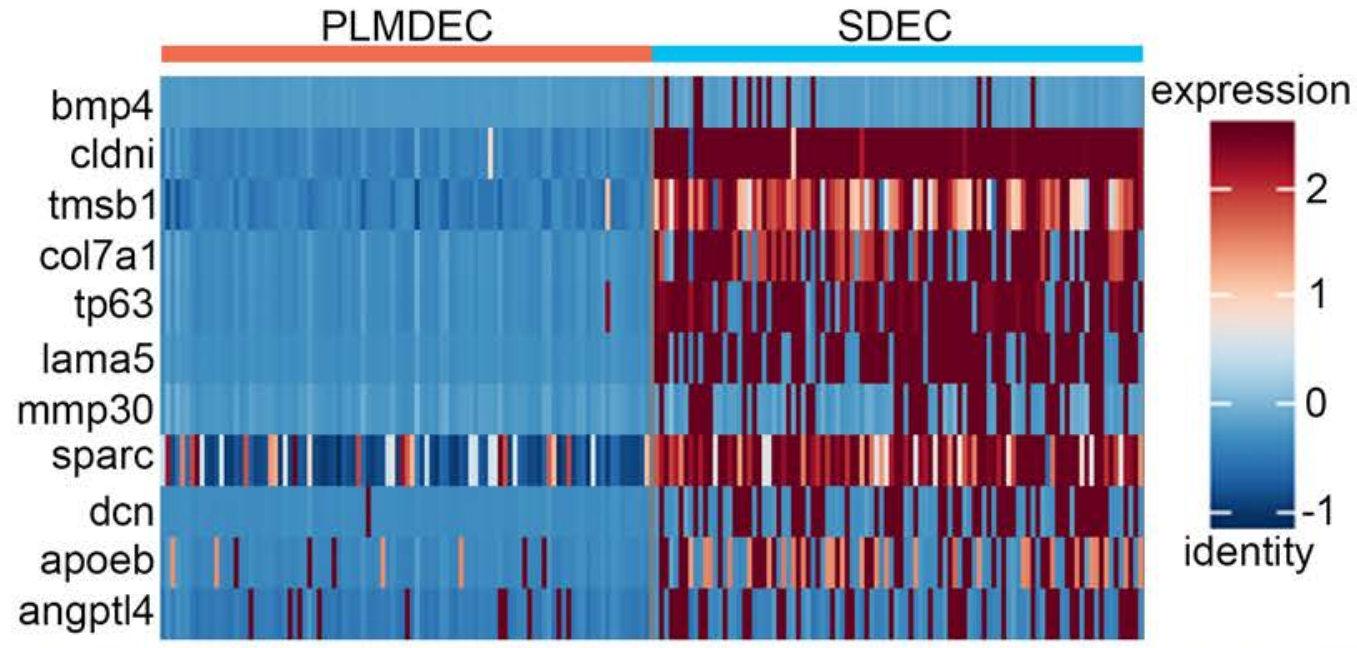

B control

runx1 C myz|2:etv2

runx1

24hpf- lateral

D control

runx1 E meox1 mo

runx1

22 hpf- lateral

F control

runx1 G meox1 mRNA

runx1

26hpf- lateral

$\mathrm{H}^{\text {control }}$

gata $2 b$

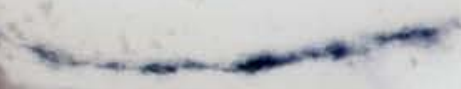

32hpf- lateral

J control

bmp4
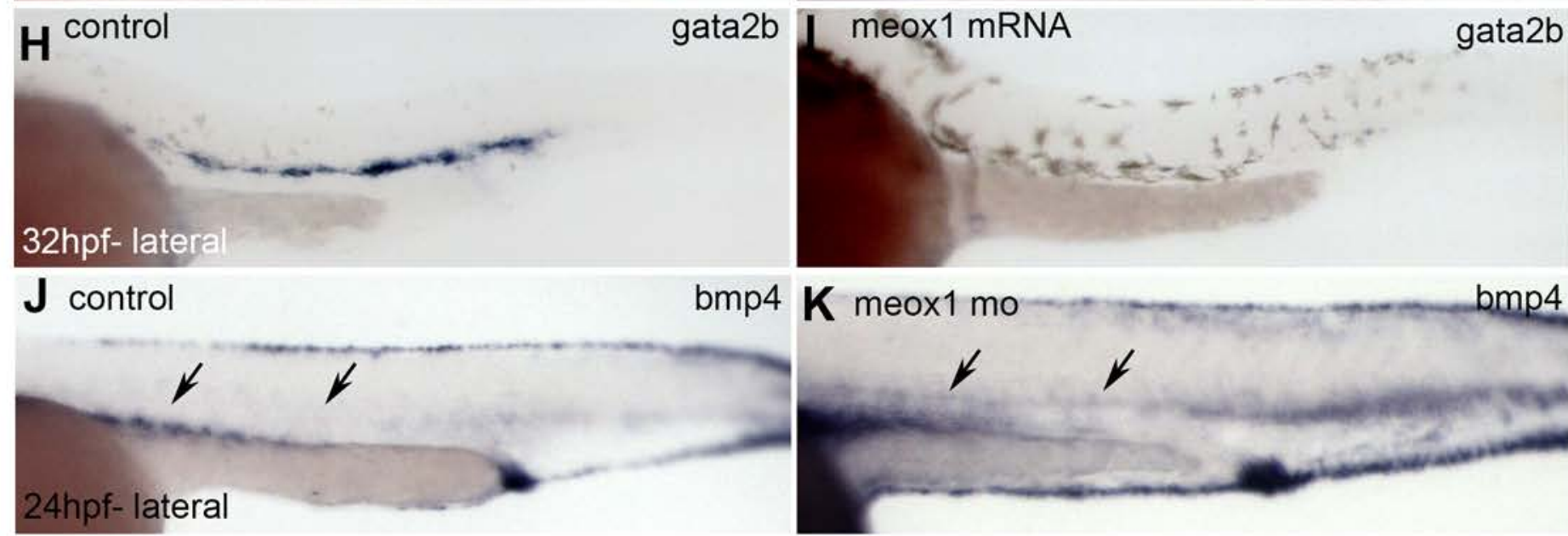

$\mathbf{K}$ meox1 mo bmp4

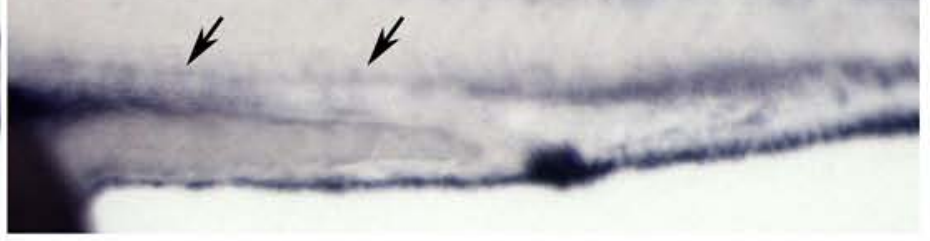




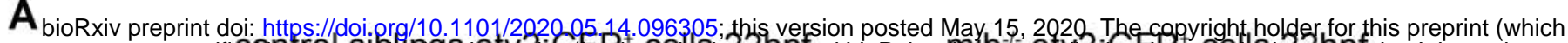

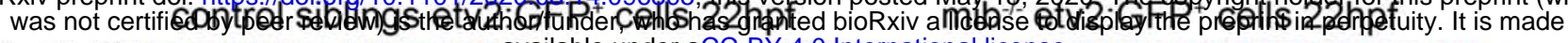
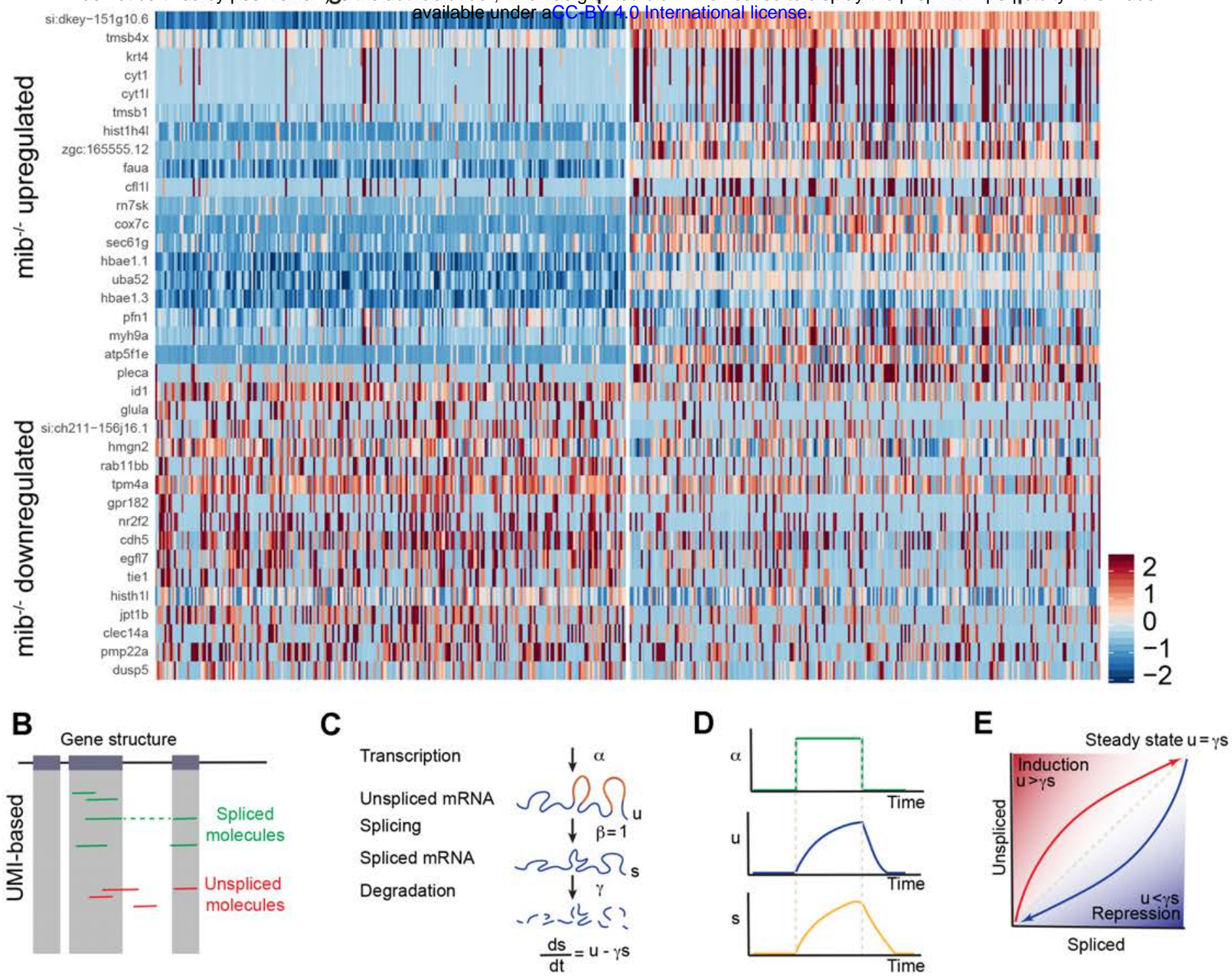

F control siblings etv2:GFP ${ }^{+}$cells at $22 \mathrm{hpf}^{\mathbf{G}} \mathrm{mib}^{-1}$ etv2:GFP+cells at $22 \mathrm{hpf}$

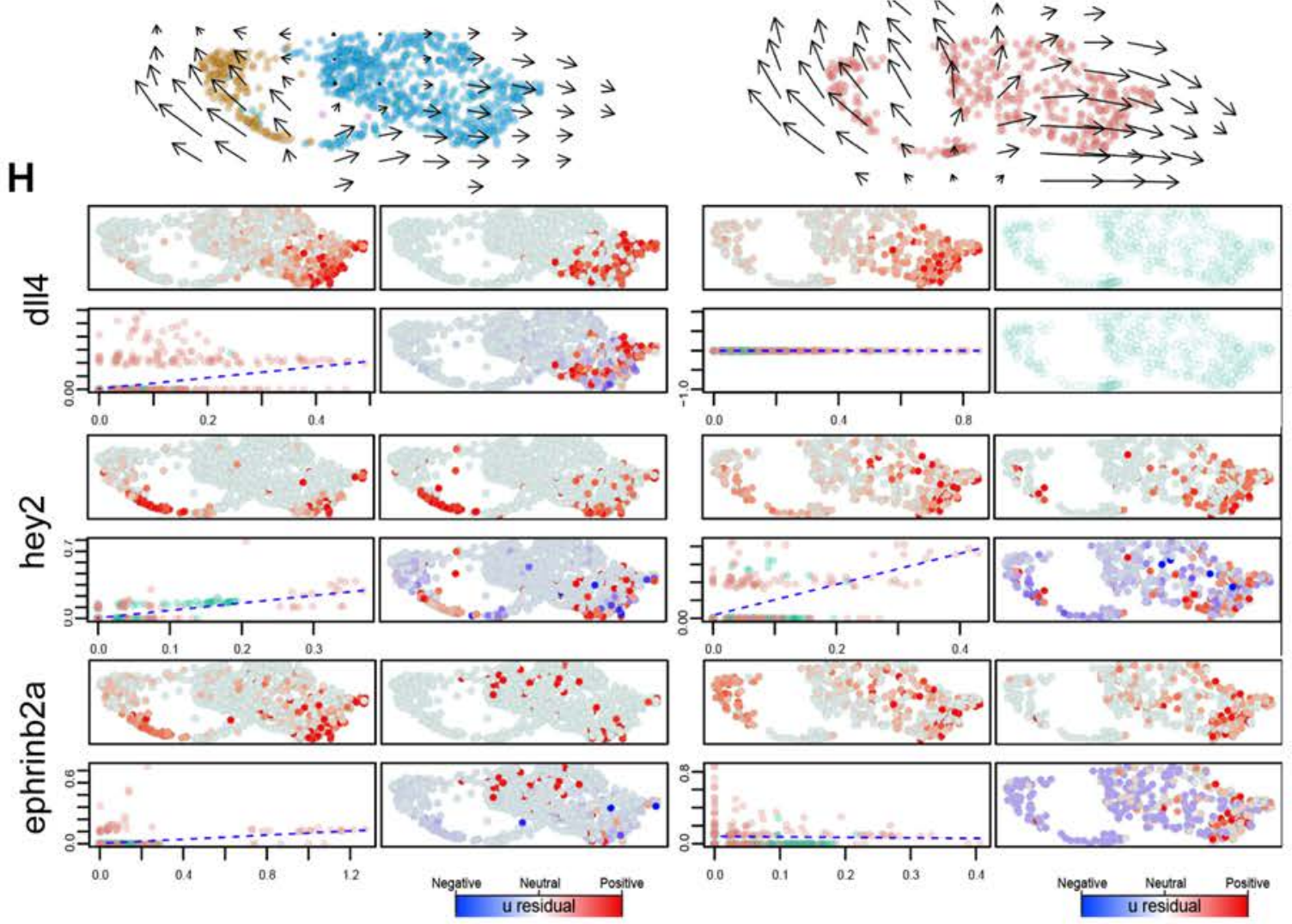




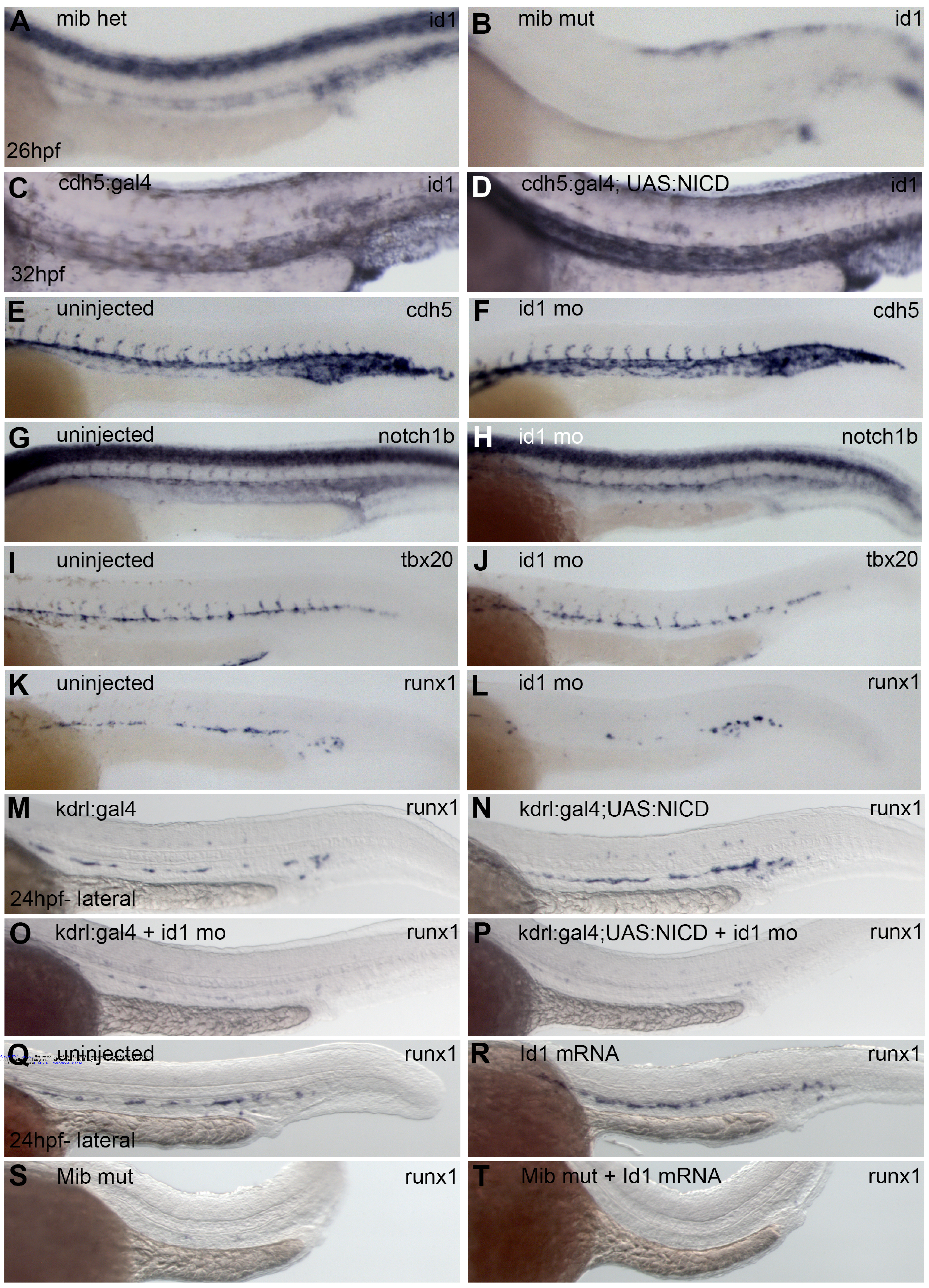


bioRxiv preprint doi: https://doi.org/10.1101/2020.05.14.096305; this version posted May 15, 2020. The copyright holder for this preprint (which

was not certified by peer review) is the author/funder, who has granted bioRxiv a license to display the preprint in perpetuity. It is made available under aCC-BY 4.0 International license.

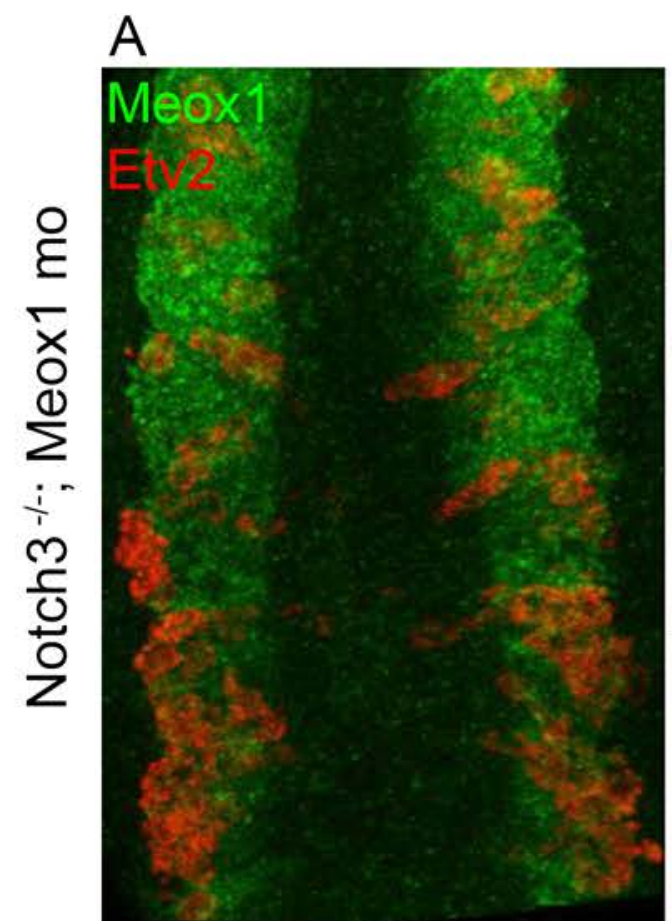

max projection
B
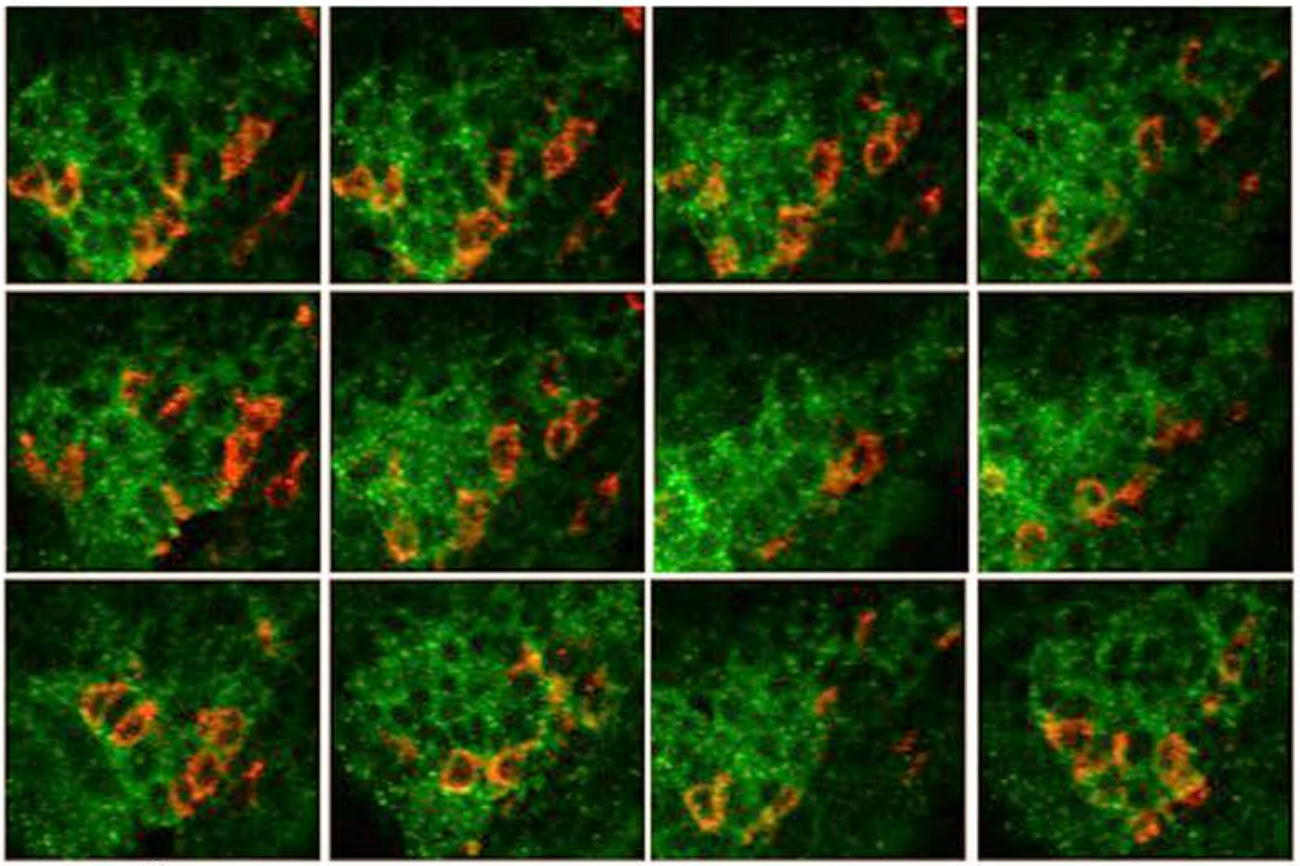

z-sections 


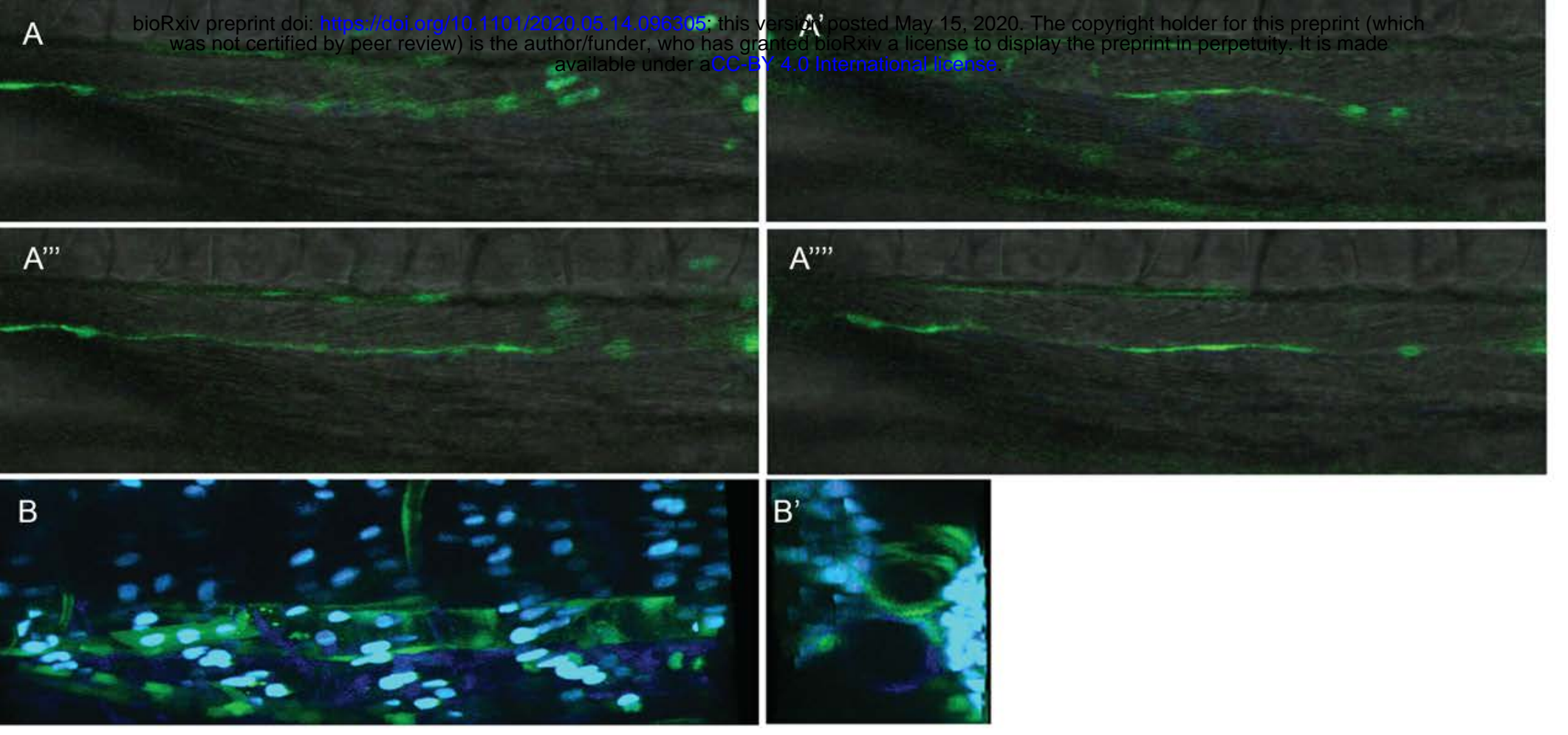


bioRxiv preprint doi: https://doi.org/10.1101/2020.05.14.096305; this version posted May 15,2020. The copyright holder for this preprint (which was not certified by peer review) is the author/funder, who has granted bioRxiv a license to display the preprint in perpetuity. It is made available under aCC-BY 4.0 International license.

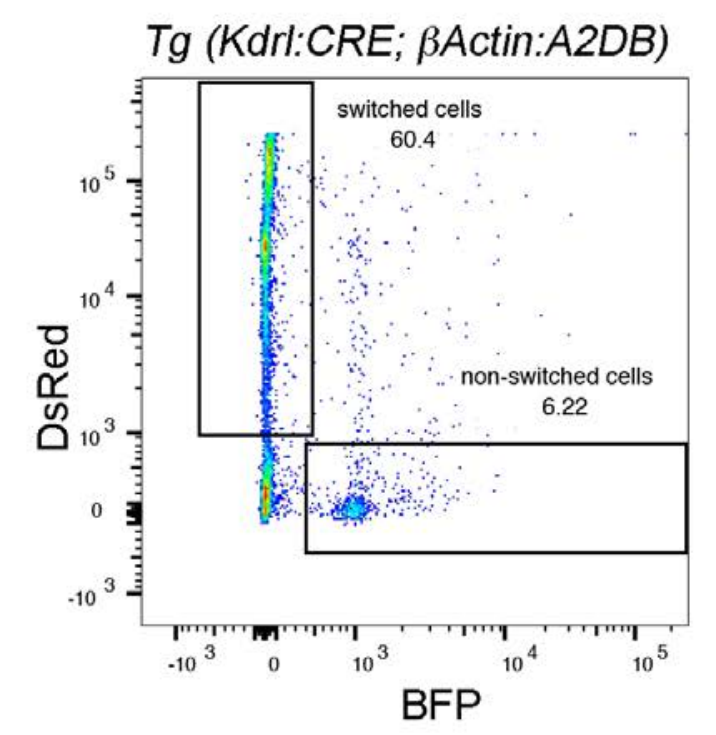

Tg (Tbx6:Gal4; UAS:CRE;

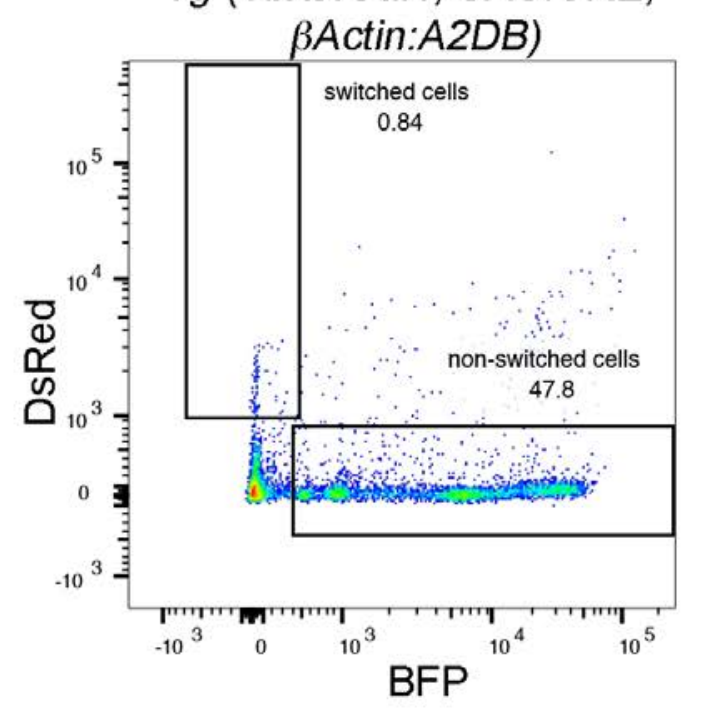

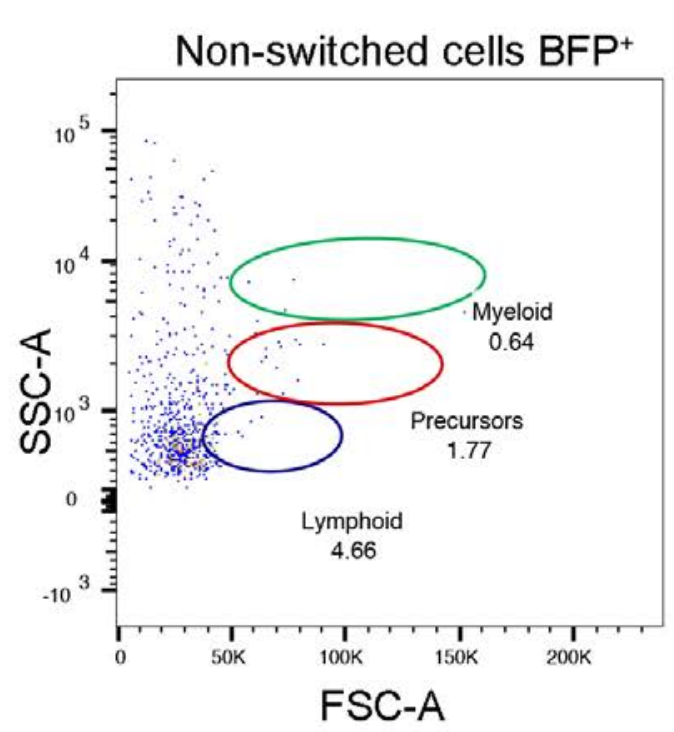
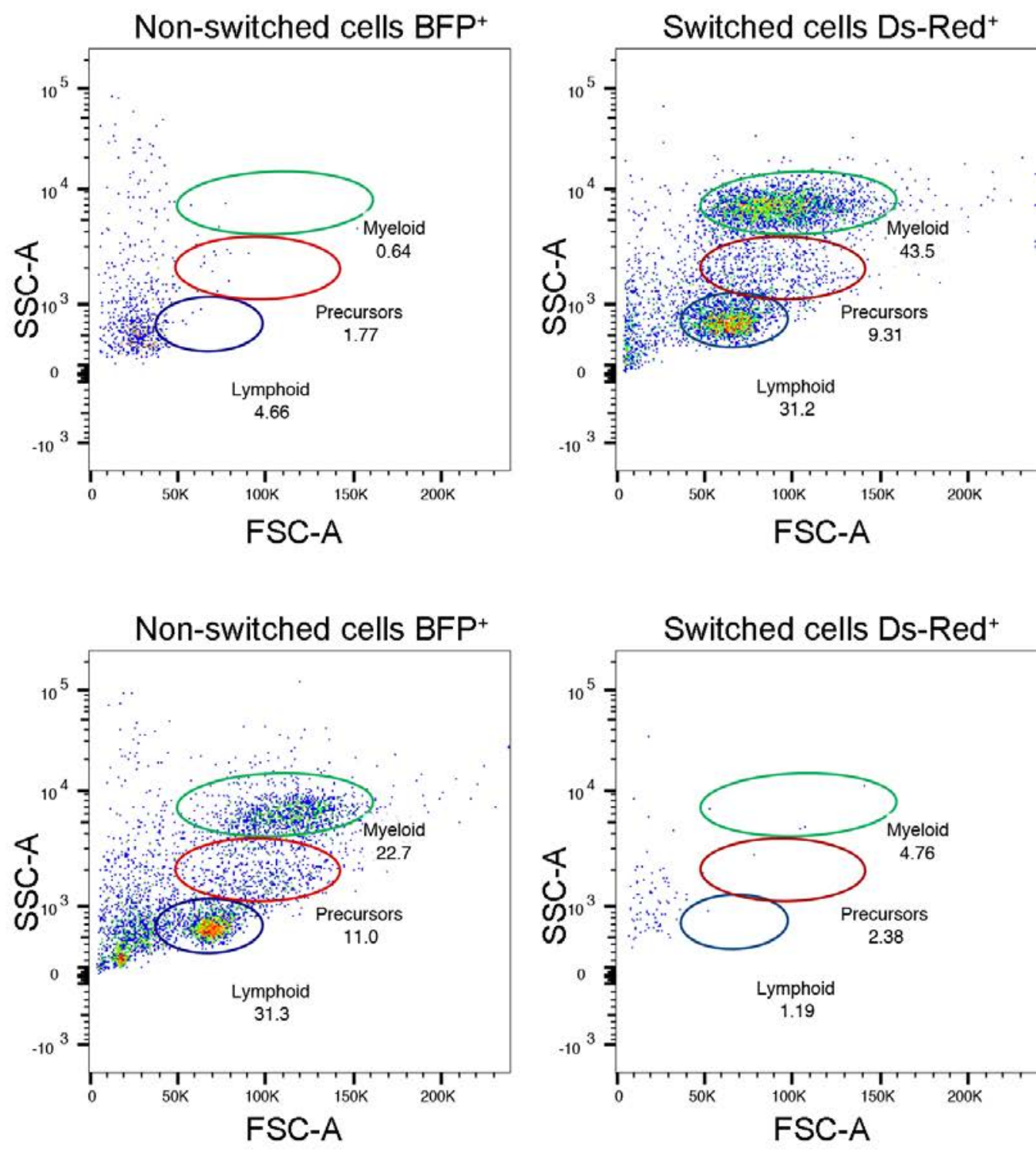
A bioRxiv preprint doi: https://doi.etg21 Qvit 1202t/2020.05.14.096305; this version posted May 15, 2020. Ethe coipyraghthpolder for this preprint (which si:dkey-151g10.6 was not certified by peer review) is the author/funder, who has granted bioRxiv a license to display the preprint in perpetuity. It is made

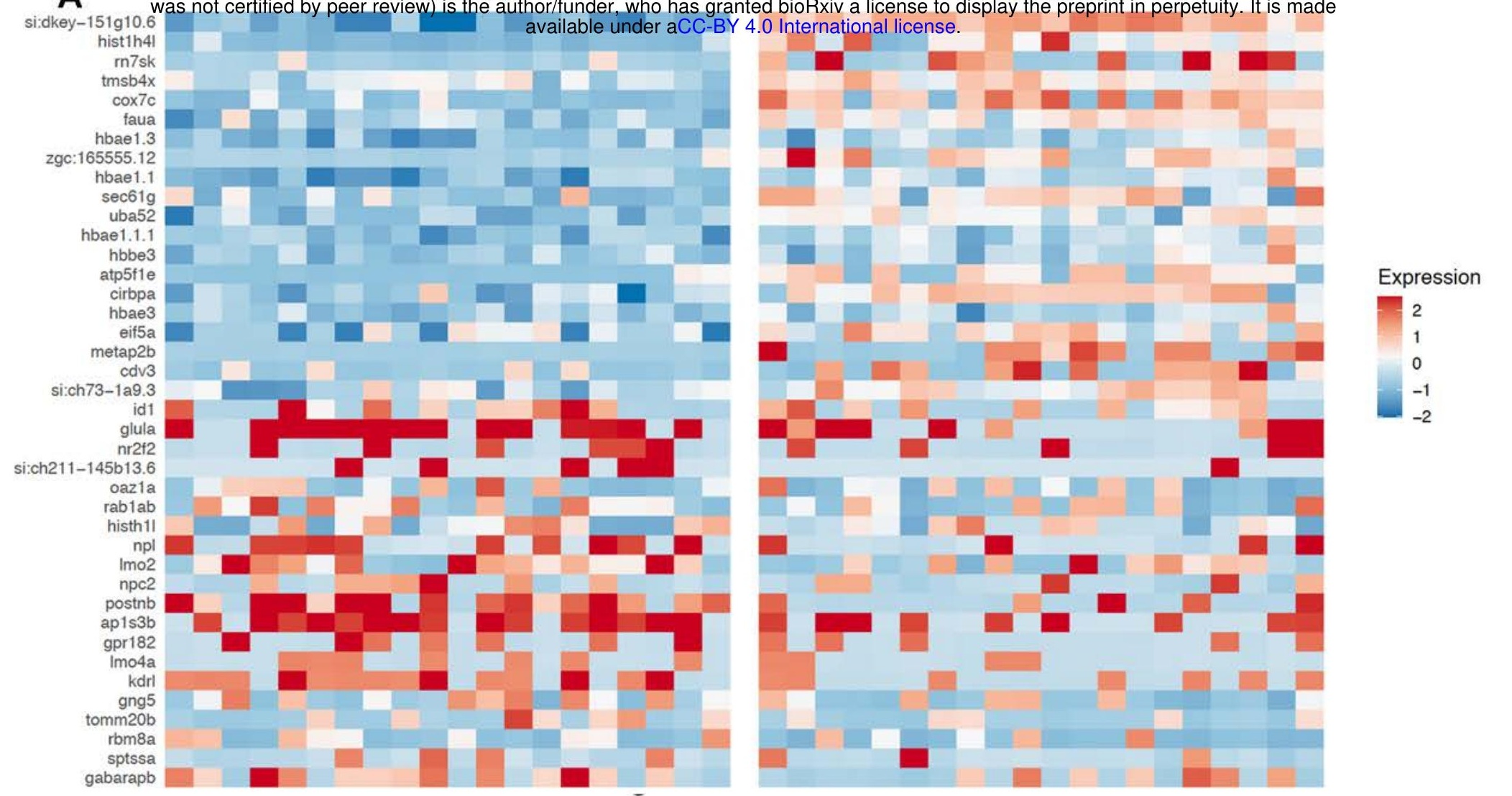

\section{B}

4 -

si:dkey-151g10.6

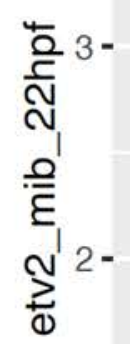


bioRxiv preprint doi: https://doi.org/10.1101/2020.05.14.096305; this version posted May 15, 2020. The copyright holder for this preprint (which was not certified by peer review) is the author/funder, who has granted bioRxiv a license to display the preprint in perpetuity. It is made available under aCC-BY 4.0 International license.

A etv2_wt_22hpf

etv2_mib_22hpf

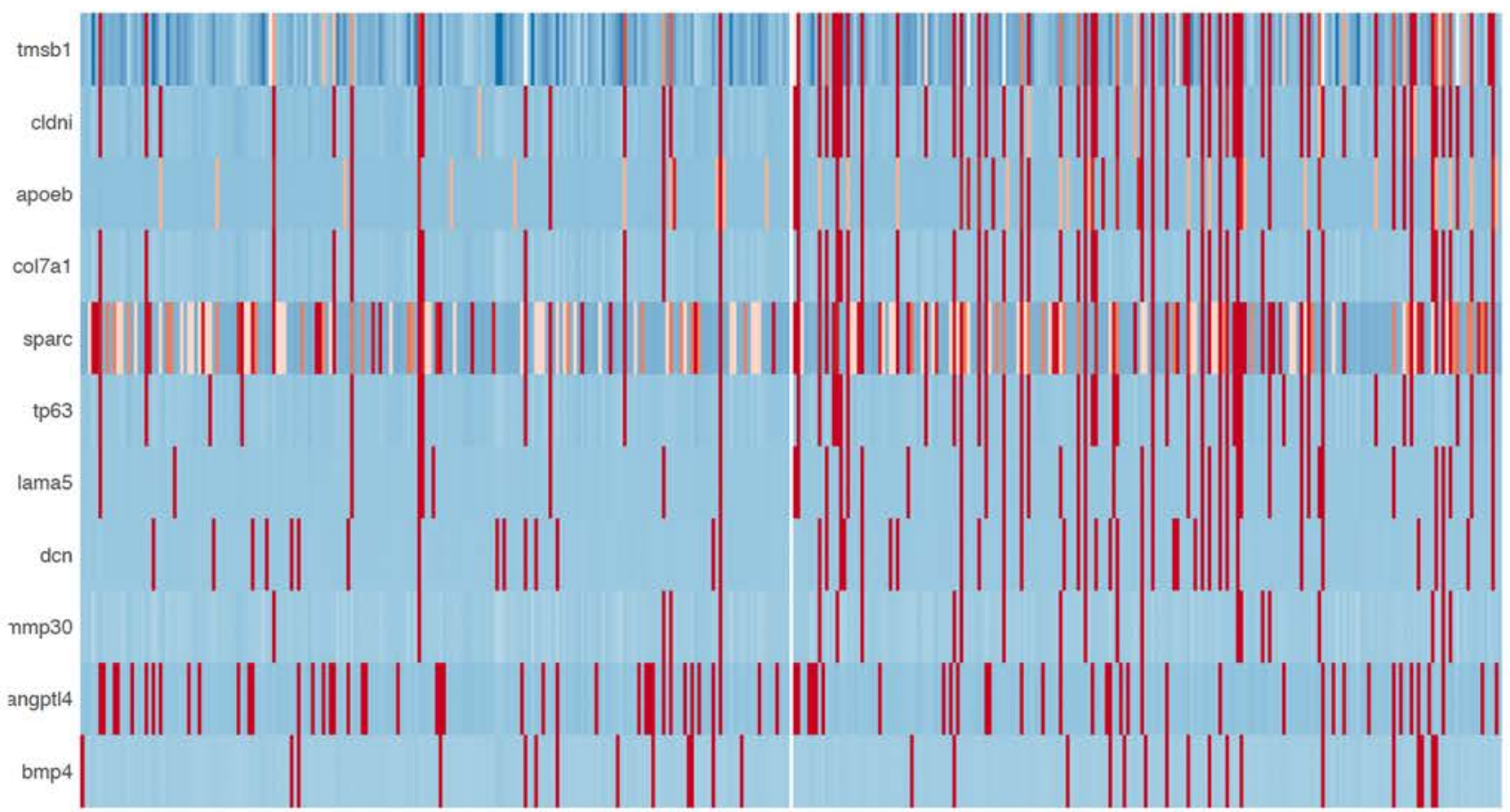

B
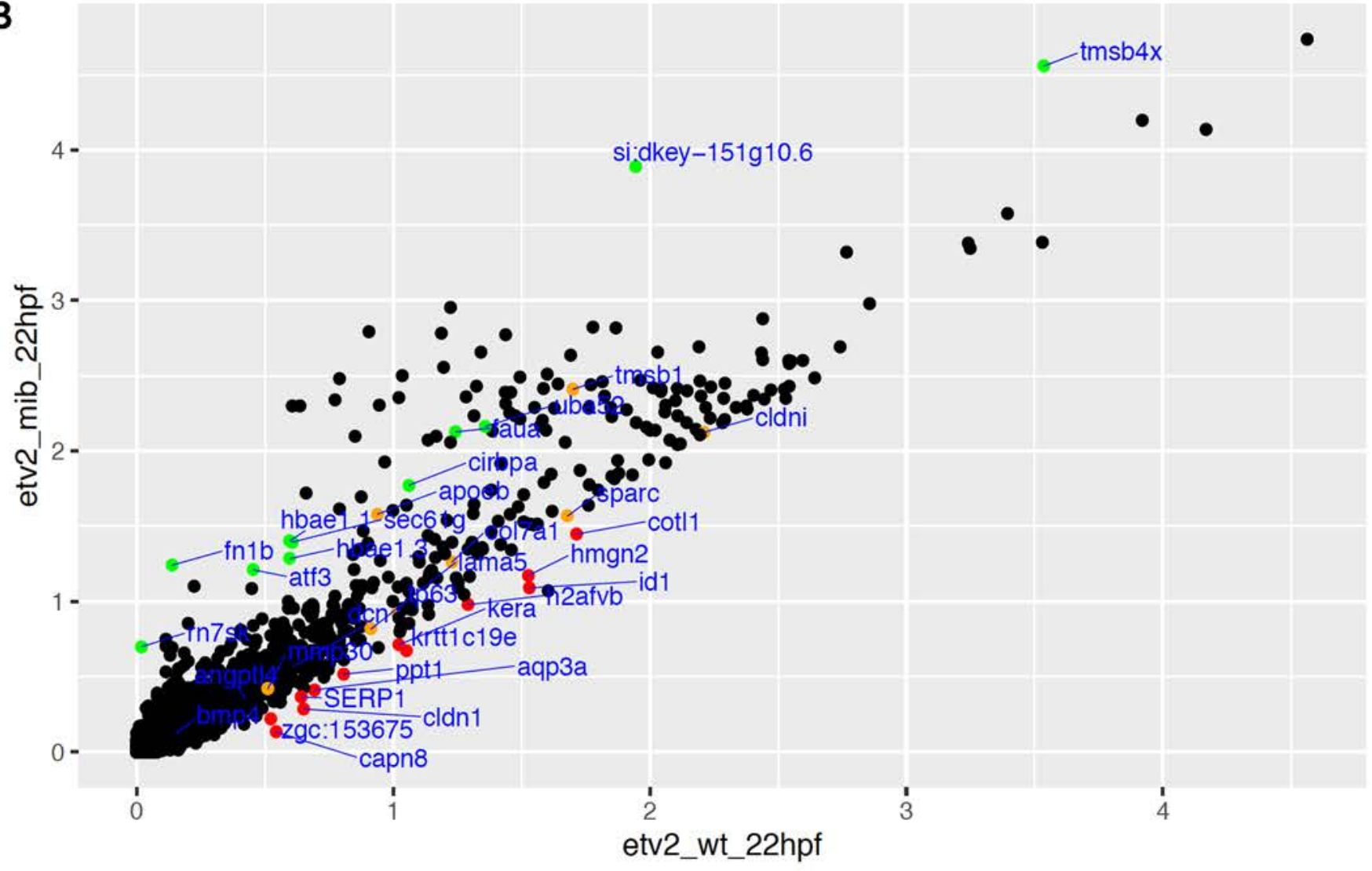
A control
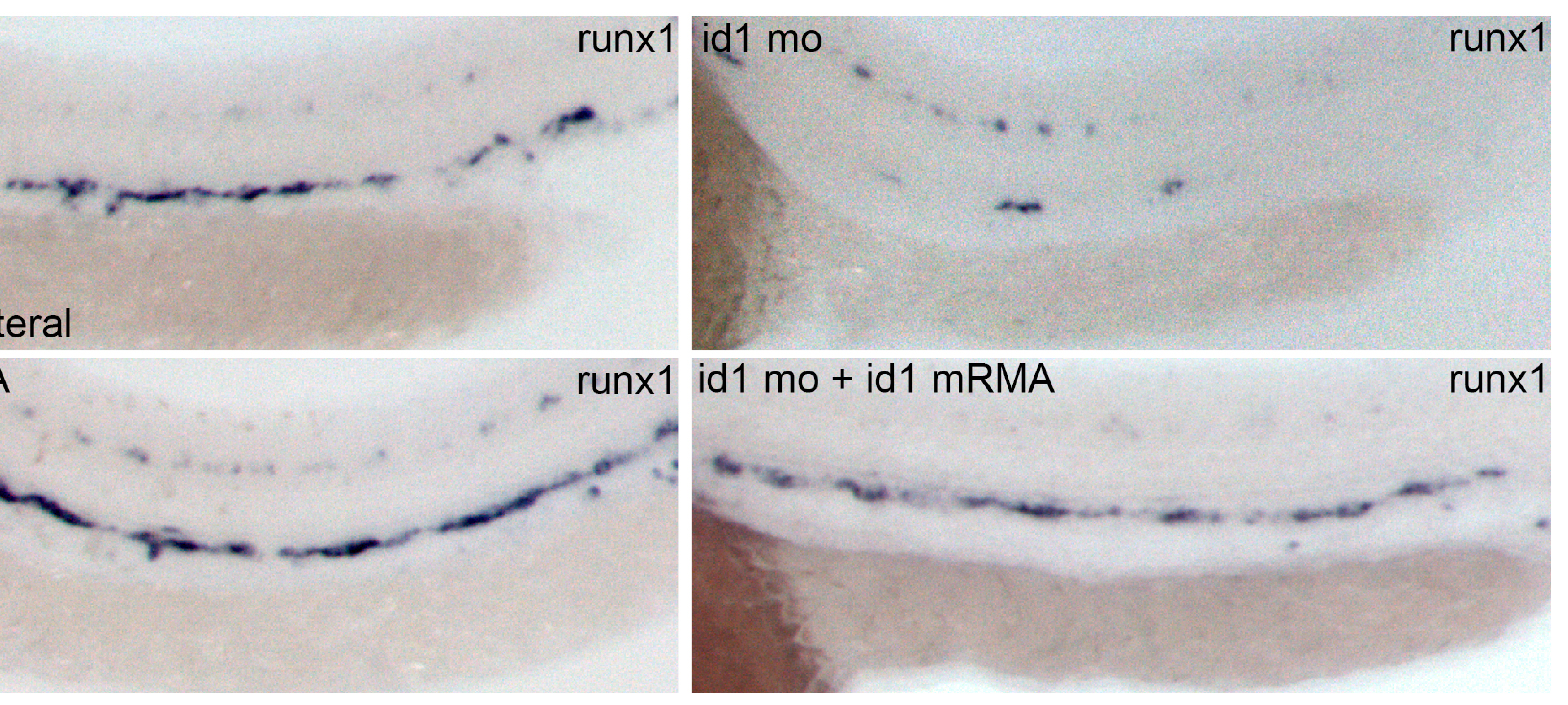

$24 \mathrm{hpf}$ - lateral

To1 mRNA

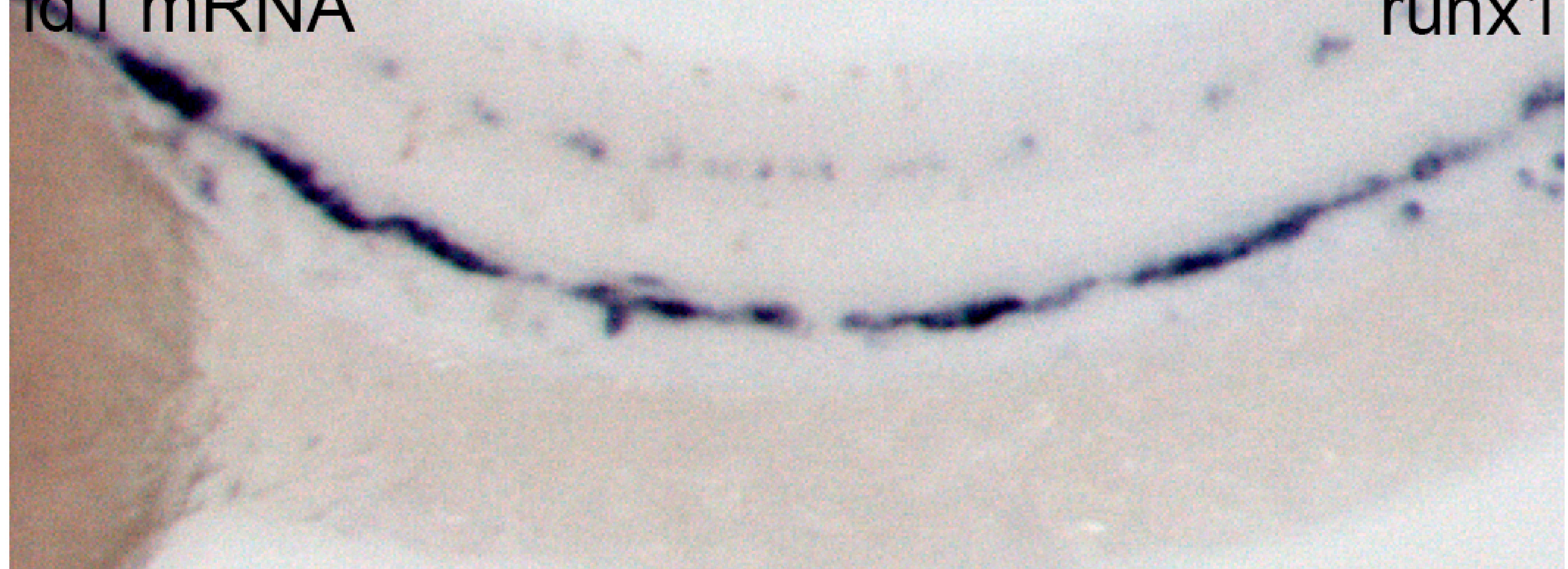

